\title{
Exploring Accounting-Sustainability Hybridisation in the UK Public Sector
}

\begin{abstract}
The transformative potential of accounting-sustainability hybrids has been promoted and problematized in the literature. We contribute to this debate by exploring, theoretically and empirically, the role of accounting in shaping and reshaping sustainability practices. We develop a holistic framework which we use to analyse the governing and mediating roles of accounting-sustainability hybrids in the Environment Agency (of England and Wales) and West Sussex County Council. Our analysis identifies that local accounting-sustainability hybrids contribute positively to improving eco-efficiency, have some impact on eco-effectiveness, but limited bearing on social justice. Emerging assemblages of accounting-sustainability hybrids create capacity for wider sustainability transformations, particularly through their mediating roles. However, a number of factors combine to frustrate further sustainability transformations within these organisations and those they are charged with governing. These factors include the structural constraints of the accounting-sustainability hybrids influenced by a relatively weak local sustainability programmatic and the pressing need to meet increasing service delivery expectations in a period of severe resource constraints.
\end{abstract}

Keywords: Sustainability programmatic, hybridisation, public sector, mediating instruments, hybrid objects, West Sussex County Council, Environment Agency, Connected Reporting Framework, UK 


\section{Introduction}

This paper explores the role of accounting in shaping and reshaping sustainability practices. Accountingsustainability processes and practices are regarded as central to embedding sustainability within public service organisations acting as intermediaries between government programmes of reform and local service imperatives. There are a growing number of accounting-sustainability hybrids ${ }^{1}$ that have been developed to embed sustainability in organisations yet our understanding of how these hybrids interact with government strategies and policies intended to change organisations and society to act more sustainably is, both empirically and theoretically, underdeveloped.

In developing our understanding of the relationships between accounting-sustainability hybrids and sustainability transformation we draw upon concepts from governmentality research (Dean, 1999; Hopwood, 1983; Kurunmäki and Miller, 2006; Miller et al. 2008). These concepts include programmatics, mediation and mediating instruments. Programmatics are high level discourses that frame and legitimate local change and articulate the plans, projects, policies, aspirations, political ideals, discursive frameworks and utopian goals of reformers. However for any change to occur there is a need to translate the aspirations of reformers into the everyday practices of local organisations. This translation or mediation is an important dynamic in any programme of transformation and normally involves a practice or object (a mediating instrument, using a term proposed by Kurunmäki and Miller (2011, p222)) that constructs points of common reference between strategic programmes of reform and local practices. In this paper we consider accounting-sustainability hybrids as mediating instruments that could translate programmes of sustainable reform into local organisations in order to enable change. Exploring the mediating potential of different accounting-sustainability hybrids offers a number of insights that could inform the evolution of hybrids aligned with sustainability programmatics.

Research into accounting and sustainability covers a diverse range of accounting processes and practices (Thomson, 2007) that can be seen as "new phenomena produced out of two or more elements normally found separately" (Miller et al., 2008: 943), combining aspects from a stable and dominant discipline (accounting) with an emerging discipline (sustainability) (Frame and O'Connor, 2010; Kastenhofer et al., 2011; Pretty, 2011). Examples of these accounting-sustainability hybrids include biodiversity audits (Jones, 1996), carbon accounting (Ball et al., 2009; Hopwood, 2009), corporate social reporting (Gray, 2010), energy costing (Bebbington, 2010), external social audits (Harte and Owen, 1987; Georgakopoulos and Thomson, 2008), full cost accounting (Bebbington et al., 2001), shadow accounts (Gray, 1997) and the sustainable balanced scorecard (Figge et al., 2002). Prior research into the effectiveness of such hybrids has concentrated on their

\footnotetext{
${ }^{1}$ In this paper we use the phrase 'accounting-sustainability' to represent a range of accounting techniques previously referred to as social, environmental, ethical and responsibility accounting. The use of the term 'accounting-sustainability' should not be interpreted as meaning that we endorse the adoption of these accounting techniques or consider them to facilitate sustainable development.
} 
role in organisational governance rather than on their potential as mediating instruments. However, most accounting-sustainability hybrids can be seen as attempting to lead on organisational change in local service delivery practices that are aligned with elements of external sustainability programmatics. These hybrids are expected to broker or mediate between exogenous and endogenous frames of reference.

In relation to this, we advance our theoretical understanding by developing a holistic framework on the governing and mediating role of accounting-sustainability hybrids in sustainable transformations within organisations. Our framework helps in analysing the process by which accounting-sustainability hybrids are selected as mediating instruments and the impact this choice has on the shaping and reshaping of local sustainability governance practices. We refine the levels of analysis suggested by prior governmentality studies (Kurunmäki and Miller, 2011) to reflect upon the complex nature of organisational changes associated with the emerging sustainability programmatic. Our holistic framework is drawn from a number of sources, including the governmentality and accounting, new public management accounting and accounting-sustainability literatures. Central to this framework is the middle layer or bridge, referred to by Kurunmäki and Miller (2011) as the mediating instrument. We develop additional insights into the relations between accounting mediating instruments and the programmatic discourses that give them form as well as local service imperatives that influence their content. In our framework we distinguish between local and non-local accounting-sustainability hybrids, with the former referring to processes and practices generated internally and the latter offered as generic solutions by external bodies.

While knowledge on internal accounting and sustainability processes and practices is sparse in the academic literature (Hopwood, 2009), this shortage is more evident in the public sector (Ball and Grubnic, 2007). Unlike profit-orientated organisations, public sector organisations in the UK have an explicit responsibility to transform along a more sustainable trajectory and, further, to lead collectively on this large-scale change (DEFRA, 2005). Public service organisations are considered part of the solution in protecting against threats to peace and security as would be the case, for example, if water and food were in limited supply or basic human rights not safeguarded. In this paper, we respond to Kurunmäki and Miller's (2011) call to investigate how government ideals are made operable through processes and practices at the unit organisational level and, in so doing, develop further links between the accounting sustainability and public administration literatures.

In the empirical section of this paper we explore the role of accounting-sustainability hybrids in the embedding of sustainability in the Environment Agency and West Sussex County Council. These organisations are both public service organisations with long-standing strategic commitments to and regulatory responsibilities for sustainability (Thomson and Georgakopoulos, 2010; Grubnic and Owen, 2010). As UK public service organisations they are subject to the same nexus of programmatic discourses and constrained by their statutory remit as to how (or whether) they implement government policy initiatives. In both of the cases, 
senior managers endorsed the use and development of the Connected Reporting Framework ${ }^{2}$, as an accounting practice for the embedding of the UK Sustainable Development Strategy (DEFRA, 2005) ${ }^{3}$ in local processes and practices. The existence of an authoritative sustainability programmatic, engagement with a common accounting-sustainability hybrid and different service delivery imperatives allows the opportunity of identifying the impact of such hybrids in the shaping and reshaping of local sustainability practices. Our empirical sites allow us to analyse accounting-sustainability hybridisation processes in order to identify how the programmatic discourse is interpreted at a local level, examine the role of local and non-local mediating instruments on local processes and practices, and assess how effectively hybrids translate the sustainability programmatic into governing processes.

The comparative case study approach combined with the holistic framework identifies a number of important empirical contributions to the literature. We provide information on how accounting-sustainability hybrids are used in two regulatory hybrid organisations responding to calls for more research in public services on sustainability accounting (Ball and Grubnic, 2007; Ball et al., 2009). Our analysis allows us to draw out key attributes of effective mediation that are of particular relevance when developing hybrids intended to be used for mediating purposes.

The rest of this paper is structured as follows. Firstly from our literature review we construct a holistic framework to analyse the development of accounting-sustainability hybrids in our case study organisations. This is followed by an explanation of the research methods including a discussion of the rationale for the case selection. We then present our findings on each case separately. We finish with some general concluding comments from our analysis of the cases incorporating a discussion of the wider implications of our holistic framework.

\section{Accounting-Sustainability Hybridisation - A Holistic Framework}

"Accounting is constantly engaged in a dual hybridisation process, seeking to make visible and calculable the hybrids that it encounters, while at the same time hybridising itself through encounters with a range of other disciplines." (Miller et al., 2008 p.945)

Prior literature has documented and developed numerous accounting-sustainability practices such as the sustainable balanced scorecard (Figge et al., 2002) and full cost accounting (Bebbington et al., 2001, Herbohn,

\footnotetext{
${ }^{2}$ Our work originates from a research project on the effectiveness of the Connected Reporting Framework (Accounting for Sustainability, 2007; Hopwood et al., 2010) as an accounting-sustainability hybrid object that connects sustainability outcomes with management decision-making and organisational actions.

${ }^{3}$ In the US, the environmental element of sustainable development is the focus of The President's Climate Action Plan (Executive Office of the President, 2013), which outlines measures for dealing with climate change. To a gathering of university students, President Obama pledged to protect future generations from catastrophic global warming, refusing to condemn them to "a planet that's beyond fixing" (Obama address, 2013). Many governments agree that it is necessary to keep global mean temperature increases to no more than $2^{\circ} \mathrm{C}$ above pre-industrial levels in order to remain within boundary conditions.
} 
2005). We consider these practices to be hybrids of accounting with different aspects of the sustainability programmatic. For example, the sustainable balanced scorecard attempts to integrate the economic, environmental and social pillars of sustainability into Kaplan and Norton's balanced scorecard (Kaplan and Norton, 1992) in order to create a coherent performance measurement system that supports the implementation of an organisation's sustainability strategy (Schaltegger and Wagner, 2006). The sustainable balanced scorecard develops a widely used management accounting practice by incorporating sustainability related metrics into existing balanced scorecards or reconfiguring the balanced scorecard containing the conventional four dimensions (for example, financial, customer, internal processes, learning and growth) to include additional dimensions, such as, stakeholders, environmental impact, social responsibility and product life cycle. The sustainable balanced scorecard attempts to co-opt the perceived strengths of conventional balanced scorecards to the task of making organisations more sustainable. Full cost accounting can also be seen as a hybrid between conventional costing, sustainability science and environmental economics. Bebbington et al. (2001) define full cost accounting as a form of costing that allows accounting and economic measures to integrate all relevant environmental and social externalities. It is argued that full cost accounting could produce costs that are compatible with a sustainable development agenda and inform public policy development (Herbohn, 2005).

Accounting-sustainability hybrids are generally understood as governing practices that seek to make visible, governable and thinkable the risks and uncertainties (Miller and O'Leary, 1993; Miller and Rose, 1990; Rose, 1991; Power, 2007) associated with the sustainability programmatic in organisations (DEFRA, 2005; Frame and Cavanagh, 2009; Russell and Thomson, 2009). Such hybrids also play a role in mediating between accounting and sustainability initiatives and in embedding sustainability programmatic discourses into local organisational processes. One such hybrid which forms part of our empirical study is the Connected Reporting Framework, an accounting-sustainability hybrid, which Fries, et al. (2010) argue was designed as a non-local mediating instrument to embed sustainability into organisations in order to bring about sustainable transformations. The Connected Reporting Framework is built upon the perceived strengths of accounting, such as robust quantitative evidence gathering, relevance, materiality, reliability, comparability and assurability, to articulate the sustainability discourse into a "language" understandable to organisational decision-makers and provide clarity for outcomes (Accounting for Sustainability, 2007; Hopwood et al., 2010).

However, most of the evaluations of the Connected Reporting Framework (e.g. Fries, et al. 2010; Lewis and Ferguson, 2010; Unerman and O'Dwyer, 2010; Bhimani and Soonawalla, 2010; Brigham, et al. 2010) focus on its effectiveness in organisational governance through the creation of greater visibility and knowledge of the financial consequences of consuming resources and the provision of a different lens to view organisational practices. Although there is some discussion on the benefits of using the Connected Reporting Framework as a mediating instrument to embed sustainability into organisations, there is very little discussion on how (or whether) the Connected Reporting Framework is selected as a suitable mediating instrument. 
We position our analysis of accounting-sustainability hybrids in the governmentality literature that has been used to explore a range of different aspects of accounting - including management accounting (Armstrong, 1994; Ezzamel et al., 2007; Miller and O'Leary, 2007; Lambert and Pezet, 2010), accounting and power (Dean, 1999; Everett et al., 2007; Rose, 1991), historical emergence of accounting (Hopwood, 1983, 1987; Hoskin and Macve, 1986), accounting and auditing in the public sector (Kurunmäki, 1999; Kurunmäki and Miller, 2006; Miller and Rose, 2008; Nyamori, 2009), accounting and organisational transformation (Kronberger and Carter, 2010; McKinlay et al., 2010; Vaivio, 2006), accounting and resistance (Neu and Heincke, 2004; Fischer and Ferlie, 2013) and accounting regulation (Mennicken, 2008).

To date there has been limited application of governmentality theories to the development of accountingsustainability practices (see, for example: Everett, 2004; Neu, 2000, 2006; Spence and Rinaldi, in press). However, such hybrids have been extensively examined and critiqued from a range of different theoretical perspectives, and concerns raised that accounting practices problematically capture the sustainability programmatic and suppress fields of visibility, forms of knowledge and techniques of governing considered essential for any sustainable transformations (e.g., Cooper, 1992; Cooper et al., 2005; Gray, 2010; LarrinagaGonzalez and Bebbington, 2001).

Given the power of accounting in contemporary modes of public sector governance (Broadbent and Guthrie, 2008; Broadbent and Laughlin, 2002; Kurunmäki and Miller, 2011; Llewellyn, 1994), we expect that our research will identify accounting, and in particular, hybrids of accounting and sustainability to be central to the (in)effectiveness of how the sustainability programmatic is hybridised into organisational processes and practices (Ball, 2005, 2007; Ball and Grubnic, 2007). In order to evaluate the role of these hybrids in organisational transformation, it is important to recognise the governing and mediating roles of accounting objects $^{4}$ (Briers and Chua, 2001; Miller et al., 2008) and, in particular, that while the governing and mediating roles of accounting hybrids are inter-related, they cannot be conflated (Wise, 1988, 1995; Wise and Smith, 1989a, b, 1990). Therefore, there is a need for a more explicit theoretical and empirical understanding of the mediating role of accounting-sustainability hybrids in order to inform the evolution of those hybrids aligned with the sustainability programmatic and address the concentration of prior research on the governing effectiveness of such hybrids.

Our review of the accounting, governmentality and hybridisation literature identifies a number of key elements, critical processes and inter-relationships associated with accounting hybridisation processes. These include understanding: the nexus of programmatic discourses framing an organisation; the potential set of non-local and local mediating instruments; the local organisational context; the construction of locally relevant hybrid programmatic discourses; the construction of locally relevant mediating instruments; and, the design and embedding of local accounting-sustainability hybrids in the governing of the organisational processes and

\footnotetext{
${ }^{4}$ We are using the term 'object' to represent physical objects, social constructs, ideas and social processes and practices.
} 
practices. From this review we constructed a holistic framework to interpret our case study findings and also to inform future research and practice development in this field.

This holistic framework contains four inter-related dimensions that collectively can be used to gain insights into how organisations respond to changes at programmatic and non-local levels. These four dimensions are: how the local organisations interpret, prioritise and construct their own locally relevant programmatic discourses; how organisations select and/or construct mediating instruments to channel the sustainability programmatic into their local accounting processes and practices; how organisations construct and embed hybrids of accounting and sustainability into their governing processes; and finally, how effectively these accounting-sustainability hybrids translate the sustainability programmatic into local governing processes. The remainder of this section will present the four dimensions individually and then discuss how these dimensions may interact in different contexts.

How organisations interpret, prioritise and construct their local programmatic discourses

One observation from our review of the literature relates to the importance of understanding the programmatic discourses that impact on organisations, in particular challenging the assumption of an identifiable programmatic discourse (Dorrestijn, 2012; Miller et al., 2008; Power, 2004, 2007). Despite a large body of empirical evidence (Ball, 2005; Bebbington and Gray, 2001; Herbohn, 2005; Lehman, 2001) many accounting sustainability studies assume that the impact of the sustainability programmatic can be isolated and that it will be a powerful force in transforming accounting and organisational practices (e.g. Figge et al., 2002; Henri and Journeault, 2010; Fries et al., 2010; Lohman, 2009). Van Helden et al. (2010) argue that organisations (including public service organisations) are framed by a complex web of competing and contradictory programmatic discourses. It is, therefore, difficult to isolate the impact of a single programmatic, such as sustainability, on a specific hybridisation event (Miller et al., 2008; Miller and O'Leary, 2007; Wise, 1988, 1990). This complex set of programmatic discourses requires public service organisations to construct their own hybrid programmatic with which to legitimate any organisational changes in terms of their identity, responsibilities, priorities, governing practices and permitted actions.

The freedom and power of organisations to construct their programmatic hybrid varies. Regulatory hybrid organisations, such as public service organisations, tend to have limited capacity to determine which programmatic discourses should influence their actions (e.g., Hyndman and Connolly, 2001; Kurunmäki, 2004; Kurunmäki and Miller, 2006; Power, 2007). The UK public sector is subject to a complex, evolving set of programmatic discourses (Ball, 2005; Kurunmäki and Miller, 2006; Lapsley and Wright, 2004; Laughlin, 2007) which include new public management, public welfare, value for money, outcome- and evidence-based governance, deregulation and competition, individual freedom, national security, economic growth, risks and most recently the austerity discourse. Sustainability is a relatively recent programmatic discourse that impacts on the governing of and governing by UK public service organisations (Ball 2002, 2005; Ball and Grubnic, 2007; Ball et al., 2009). There are considerable commonalities between public service values and the sustainability programmatics, but there are also significant differences (Ball and Grubnic, 2007; Boyne, 2002; Broadbent and 
Guthrie, 2008; Lehman, 2001). Our review of the literature suggests that the impact of the sustainability programmatic will be mitigated by the impact and/or alignment with other programmatics that frame individual organisations. Therefore when analysing any accounting-sustainability hybridisation it is important to explore how organisations integrate elements of the sustainability programmatic into their local programmatic discourses.

How organisations select and/or construct mediating instruments to channel the sustainability programmatic into local accounting processes and practices

There are a number of studies that identify the importance of understanding how mediating instruments impact on organisational and accounting transformations. It is recognised that mediating instruments impose structural constraints on any hybridisation by defining the points of common reference from which any integration could emerge (Miller et al., 2008; Miller and O'Leary, 1987; Wise, 1988, Wise and Smith, 1990). Mediating instruments allow the mutual recognition of potential hybridisations, but any hybridisation possibilities are restricted by the extent to which the mediating instrument fully represents the points of commonality. The importance (and problems) of accounting objects operating as mediating instruments in driving or shaping organisational transformation is well established (Miller et al., 2008; Hopwood, 1983; Hoskins and Macve, 1986; Radcliffe, 1998) and is recognised in the accounting-sustainability literature (e.g., Gray et al., 1995; Puxty, 1991; O’Dwyer, 2003b, 2005). However, there is a lack of exploration as to how (or whether) such hybrids are selected as mediating instruments. As discussed earlier in this section the Connected Reporting Framework is one example of an accounting technique that conflates the mediating potential of accounting-sustainability hybrids with how fully they represent the sustainability programmatic (e.g., Gray et al., 1995; Henri and Journeault, 2010; McKenzie, 2009; Russell and Thomson, 2009).

In order to develop our understanding of accounting-sustainability hybrids' mediating potential in contemporary organisations we draw upon mediation in the history of science literature (Cleaver, 1989; Lenoir, 1988; Levallois, 2011) and, in particular, the work of Wise $(1988,1995)$ and Wise and Smith $(1989 a, b$, 1990). These works identify a number of important characteristics of objects that influence their possibility of being selected as mediating instruments. One rather counter-intuitive observation is that it is the general awareness of an object rather than its technical or conceptual sophistication that affects its selection for mediation. A number of authors conclude that all parties to any hybridisation must accept a mediating instrument as legitimate and relevant to them in order for hybridisation to occur (Wise, 1988, 1995; Wise and Smith, 1989a, b, 1990). Therefore a mediating instrument needs to be understandable by all parties in the context of their individual knowledge and experiences.

Typically mediating instruments are ubiquitous objects that play a visible and observable part in different contexts. For example, Wise (1988) describes how the steam engine and telegraph cable operated as mediating instruments in the integration of physical science, political science and engineering disciplines in the 19th century. Actors from different scientific disciplines were able to relate and understand these objects on both practical and theoretical levels, considered them to offer generalisable and plausible translations of other 
theories, practices and values and thus were accepted as mediating instruments (Wise and Smith, 1989a, b, 1990).

Wise (1988) discusses how people can find it difficult to accept novel programmatic discourses as more relevant than their everyday experiences that have remained relatively stable over time despite previous radical changes in the programmatic level. His work suggests that individuals are less likely to choose non-local objects to create mutually acceptable frames of reference between a novel programmatic (such as sustainability) and their local organisational processes and practices. Drawing on the work of Wise and others (Cleaver, 1989; Lenoir, 1988; Levallois, 2011; Wise and Smith, 1990), it is more likely that generally understood everyday objects will be selected to translate or embed programmatic discourses into local processes and practices, regardless of non-local objects' conceptual or practical appropriateness for the task.

How organisations construct and embed hybrids of accounting and sustainability into their governing processes There is a large body of work that identifies the criticality of a shared calculative rationality and the calculability of "the other" in the development of accounting hybrids, including accounting-sustainability hybrids (e.g., Fischer and Fearlie, 2013; Gouldson and Bebbington, 2007; Gray et al., 1997; Lambert and Pezet, 2010). Calculation and calculability appear to be central to the identity and underlying rationality of accounting and accountants. This suggests that without the possibility of calculating "the other" there would be very little possibility of accounting hybridisation. It is difficult to see how accounting and sustainability hybridisation would be substantially different from the hybridisation of accounting and other domains or discourses. Therefore the most likely hybridisation route would be through the calculable risks and uncertainties of unsustainable development. Elements of sustainability that have been or can be calculatively captured possess the greatest potential for accounting-sustainability hybridisation. The wide-ranging literature on social and environmental accounting, reporting and auditing practices tends to support this observation and many authors express concerns over what they regard as the inherent incalculability of sustainability programmatic discourses (e.g., Maunders and Burritt, 1991; Georgakopoulos and Thomson, 2005, 2008, 2012). Another important observation is the possibility of the local resistance in shaping the development of accountingsustainability hybrids (Armstrong, 2006; Broadbent et al., 2001; Kurunmäki et al., 2003; Miller et al., 2008).

Many accounting-sustainability hybrids (such as the sustainable balanced scorecard, Connected Reporting Framework, full cost accounting) appear to be designed as generic accounting practices informed by programmatic discourses with little consideration for local organisations and their capability to change preexisting service delivery imperatives. In many cases accounting hybridisation appears to be driven by intraorganisational dynamics decoupled from programmatic discourses or framed by mediating instruments constructed from local processes and practices (Miller et al., 2008). Prior studies note the complex interplay between programmatic and local levels in the development of accounting hybrids and how the same set of programmatic discourses do not produce the same local governing processes, practices or outcomes. In our study both organisations are part of the UK public sector rather than the large publicly listed companies that 
form the basis of most accounting-sustainability research papers (Thomson, 2007). Arguably this creates the possibility of a different set of accounting-sustainability hybrids, as public service organisations have responsibilities for governing social, economic and environmental risks (Ball, 2002, 2005; Ball and Grubnic, 2007) and are more likely to have calculative measures of social inequality, social justice, economic inequality and environmental damage.

How effectively organisational accounting-sustainability hybrids translate the sustainability programmatic into local governing processes

A recurrent theme from our literature review is the need to evaluate the extent to which accounting hybrids represent programmatic discourses in organisational practices and processes (Broadbent and Laughlin, 2005, 2008; Kurunmäki and Miller, 2011;Llewellyn and Northcott, 2005). For example, prior research into UK public sector reforms using accounting mediating instruments notes that the emergent accounting hybrids have not always been aligned with the state's programmatic and distorted the aspirations of the intended reform (e.g., Broadbent and Guthrie, 2008; Broadbent et al., 2001; Hyndman and Connolly, 2001; Kurunmäki et al., 2003). Prior research suggests that the scope of accounting-sustainability hybrids will impact on its sustainable governing and transformative potential (Frame and Cavanagh, 2009; Larrinaga-Gonzalez and Bebbington, 2001; O'Dwyer, 2003b, 2005). Generally the closer the alignment of any accounting-sustainability hybrid with the sustainability programmatic then the more likely it will problematise existing actions and evaluate future decisions in line with sustainability transformation (Cooper et al., 2005; Frame and O'Connor, 2010; Harte and Owen, 1987; Russell and Thomson, 2009). However, much of the prior research identifies that most accounting-sustainability hybrids only incorporated eco-efficiency aspects of the sustainability programmatic, associated with "win-win” environmental measures (Figge et al., 2002; Gray et al., 1995; Gray, 2010; Henri and Journeault, 2010). This privileging of eco-efficiency in such hybrids creates a potential structural problem when these hybrids are used in a mediating role and may restrict any embedding of the sustainability programmatic related to social justice, community development or eco-effectiveness ${ }^{5}$.

The reflexive relationships among the programmatic, mediating and local practice levels

The final observation from our literature review is the reflexive nature of accounting hybridisation processes in organisations. Miller et al. (2008) note that "hybridising is a continually inventive process, in which proliferation and multiplication is the norm" (p.961.). The creation of a new accounting hybrid does not only change the accounting processes and practices but can change "the other" (e.g., engineering, medicine, health and safety, research and development, marketing, medicine, teaching, risk management) and the wider societal context (Armstrong, 1994; Rahaman et al., 2007; Walker, 2010; Young, 1995). The adoption and implementation of a new accounting hybrid can substantively alter the organisation through both its governing and mediating potential. It can trigger a wider series of changes (see Armstrong, 2006; Miller and O'Leary,

\footnotetext{
${ }^{5}$ Eco-efficiency is concerned with reducing the resources consumed to meet a given social or environmental objective without questioning the sustainability of that objective. Eco-effectiveness involves problematising and redefining these objectives to be in alignment with the sustainability programmatic and its focus is on systematic changes to enable sustainable transformation.
} 
1993) through creating new problematisations and possibilities for change, through new accounting hybrids acting as mediating instruments to link previously distinct parts of the organisation and facilitating and shaping further transformation (Briers and Chua, 2001). This is not always a positive phenomenon and these secondary level changes driven by accounting hybrids can lead to a colonisation of organisations by accounting rationality and governing techniques, such as the spread of New Public Management in the UK and other countries.

Prior research into accounting hybridisation suggests that accounting-sustainability hybridisation processes will not follow a "non-local to local" trajectory but may include "local to non-local" and "local to local" dynamics. Given the continual nature of accounting hybridisation in local settings (Miller, et al., 2008) the subject of analysis should not be a single hybrid but rather the evolving assemblage of accountingsustainability hybrids (Miller and O'Leary, 1993, 1994) within the organisation. The impact of any hybrid should be evaluated in the context of the local bundle of accounting practices and any potential synergistic impacts they carry.

Adopting our holistic framework enables the researcher to observe sequences of inter-connected transformations. The holistic framework developed in this section provides additional insights into our theoretical understanding of how to facilitate the development of more effective assemblages of accountingsustainability hybrids and how to analyse their emergence in practice. We will now outline the research methods used in this study, including case selection criteria and how we analysed the case studies.

\section{Research Methods}

In order to explore the role of accounting-sustainability hybrids in the embedding of the sustainability programmatic into the local practices of the Environment Agency and West Sussex County Council, we selected a comparative case study research approach (Yin, 2003). This research design allowed insights into the choice and suitability of local and non-local accounting practices as mediating instruments, and into the impact they have on the integration of a common and authoritative sustainability programmatic. In particular, we sought to identify what aspects of the programmatic are rendered visible, calculable and governable by these local accounting-sustainability hybrids.

The rationale for choosing our case organisations was four-fold. Firstly, both organisations are regulatory hybrids and subject to the same nexus of programmatic discourses including the UK Sustainable Development Strategy (DEFRA, 2005). Secondly, both organisations have long-standing strategic commitments to sustainable transformation and are considered to be exemplars in this area in the UK public sector (Thomson and Georgakopoulos, 2010; Grubnic and Owen, 2010). Thirdly the Environment Agency and West Sussex County Council were trialling the Connected Reporting Framework to further embed the sustainability programmatic (DEFRA, 2005) into their local processes and practices, Fourthly, while both organisations have regulatory responsibilities associated with sustainability, the nature of these responsibilities differ substantively. 
Therefore, while the two case organisations exhibited similarities to justify comparative analysis they also presented sufficient differences. For example, while West Sussex County Council has some responsibilities for the environment, more of its legal responsibilities and service delivery imperatives are concerned with social welfare, social justice and community building. Therefore West Sussex County Council has more potential for embedding social justice dimensions into its accounting-sustainability hybrids than the Environment Agency. The Environment Agency has some responsibilities in relation to social and economic matters but most of its responsibilities, service delivery imperatives and accountability relationships have to do with climate change and environmental protection. The Environment Agency should, therefore, possess more potential for embedding eco-efficiency and eco-effectiveness into its practices, including regulating others to improve resource efficiency, reducing waste and harmful emissions as part of a transformation to a low carbon economy.

In the UK public sector the sustainability programmatic is articulated through a series of sustainability strategies adopted by the relevant UK parliaments, for example the UK Sustainable Development Strategy (DEFRA, 2005). These strategies are collections of policies, programmes and proposals to transform all aspects of UK life including public service organisations. Public service organisations are not only required to transform their practices but also the way they govern others, while remaining within their statutory limits to act. While we do not discuss how effectively these strategies capture global political and scientific sustainability discourses, we interpret the UK Sustainable Development Strategy (DEFRA, 2005) as an official representation of the UK government's sustainability strategy in England and Wales that forms part of the nexus of programmatic discourses that frame our case organisations. The UK sustainability strategy is consistent with the underlying liberal ideology that currently informs the governing of the UK (Dean, 2007; Oels, 2005; Russell and Thomson, 2009). The UK Sustainable Development Strategy (DEFRA, 2005) presents sustainability as a model for the good governance of a civilised, responsible society that attempts to balance social justice, community building and equality of opportunity with environmental protection and enhancement and strong economic growth.

Our research methods were emergent in nature when investigating the case studies. Methods and themes codeveloped as the data and interpretations accumulated, allowing each interview to build on previous findings. Representatives from the organisation(s) were interviewed until a degree of empirical saturation was reached. In addition, we examined and incorporated into our analysis a range of documents including strategy statements, webpages, policy documents, internal reports and annual accounts. These secondary sources were analysed using themes developed from an initial analysis of the interview data.

The interviews in the Environment Agency and West Sussex County Council were undertaken in the period April to August 2009. Table 1 outlines the job description or title of those interviewed. In both cases the interview process began with a general round-table discussion with initial contacts to explore the scope of our research and identify key organisational representatives to interview. We attempted to develop understanding 
from a range of different disciplines operating within both organisations rather than limit interviews to accounting-related employees. The employees interviewed included chief executives, accounting staff, staff who designed the accounting-sustainability hybrid practices and processes, staff who operated the accountingsustainability hybrid practices and staff who used the accounting-sustainability hybrid practices and processes. In addition, we were able to interview a member of the Environment Agency's Board of Directors, who was also chair of the Audit Risk and Governance Committee and an elected member of West Sussex County Council holding the position of Cabinet Member for Finance and Resources.

The range of representatives interviewed allowed the exploration of accounting-sustainability hybridisation from multiple perspectives such as different levels of management, expertise and practical experiences. All but one of the interviews were conducted on site, the remaining interview being conducted by telephone.

Table 1 here

Almost all of the interviews lasted approximately one hour. Interviewees were co-operative, open, friendly and supportive. All interviews were recorded and summary notes written up as soon as possible after the event. The interviews were transcribed and the transcripts analysed using protocols described by O'Dwyer (2003a). Emerging themes were informed by notes taken, post-interview discussions and documents provided by the case organisations.

By systematically comparing interview transcripts, we were able to discern the factors that influenced strategic decisions on implementing and promoting sustainability, evidence of the mechanisms associated with accounting-sustainability hybridisations and perceived problems and obstacles to the embedding of sustainability. Our interview protocols allowed us to gather information from different positions and perspectives within the Environment Agency and West Sussex County Council and to sense check their "description" with that provided by others and the available documentary evidence.

In our analysis, we considered for each case the relationships between mediating instruments, programmatic discourses and local practices and the relationships within these levels. This holistic analysis provided insights into how organisations interpret, prioritise and construct their own locally relevant version of the nexus of programmatic discourses; how these organisations select and/or construct mediating instruments to channel the sustainability programmatic into their local accounting processes and practices; how these organisations construct and embed hybrids of accounting and sustainability into their governing processes; and finally how effectively these accounting-sustainability hybrids translated the sustainability programmatic into local governing processes. The next two sections apply this framework to interpret and present the evidence gathered from the Environment Agency and West Sussex County Council.

\section{Accounting-Sustainability Hybridisation: The Environment Agency}


The interpretation, prioritisation and construction of the local programmatic discourse

The publication of the UK Sustainable Development Strategy (DEFRA, 2005) did not bring about a radical transformation in the Environment Agency's programmatic discourse, but it strengthened their position and legitimacy within the UK regulatory framework. Since 1996 The Environment Agency ${ }^{6}$ has played a central role in delivering the environmental objectives of the UK government (www.environmentagency.gov.uk/aboutus/default.aspx), including promoting sustainability. Their strategy document ${ }^{7}$ (Environment Agency, 2006) outlined their five key roles as follows:

"We will

- Work directly to tackle environmental problems as an efficient operator

- Work with businesses as a modern regulator to help them reduce their effect on the environment.

But we can't do it all ourselves. We also need to:

- $\quad$ Be an influential adviser and an effective partner, persuading others to act and to work with us

Highlight the problems facing the environment and explain the need for action as an active communicator.

And we will:

- $\quad$ Be the champion of the environment (in the context of sustainable development) and advise on environmental issues, whilst taking account of economic and social issues."

(Environment Agency Corporate Strategy 2006-2011, p.3) (Emphasis added by authors to denote links to other programmatic discourses.)

The Environment Agency Corporate Strategy (Environment Agency, 2006) contained a number of key attributes from other UK public sector programmatic discourses (see bold above), for example: new public management, public welfare, value for money, deregulation and competition, partnership working and economic growth and risk management (e.g., Lapsley and Wright, 2004). The Agency adopted into their local programmatic elements of the UK Sustainable Development Strategy (DEFRA, 2005) that were aligned with their existing portfolios of powers and responsibilities, for example climate change ${ }^{8}$, pollution prevention, regulation and eco-efficiency. We considered the Environment Agency to be a regulatory hybrid organisation (see Power, 2004, 2007) and despite their support of the UK Sustainable Development Strategy (DEFRA, 2005),

\footnotetext{
${ }^{6}$ The Environment Agency was created in 1996 by the merger of National Rivers Authority, Her Majesty's Inspectorate of Pollution and other waste regulation authorities. Many of the Agency's accountingsustainability hybrids can be traced back to, for example, the National Rivers Authority Environmental Reporting established in 1987.

${ }^{7}$ Note that their Strategy document for 2010-15 (Environment Agency, 2009) also contained a similar blend of these programmatics, but their vision statement contained a stronger emphasis on people and community. We focused on the 2006-11 Strategy as this was active during the main period of our fieldwork.

${ }^{8}$ The Climate Change Act (2008) granted the Environment Agency powers to enforce the UK's carbon emission reduction regime. (accessible http://www.legislation.gov.uk/ukpga/2008/27/contents)
} 
they argued that as an Executive Public Body of the UK Government they had limited scope to change beyond their statutory remit. This was described by the Environmental Finance Manager as follows: "Its [Environment Agency's] focus is very much around environmental things, so you know, putting a lot of time and effort beyond the environmental connection would be more difficult for us." However, many of the risks contained within the UK Sustainable Development Strategy (DEFRA, 2005) associated with unsustainable development were considered potentially catastrophic and in need of urgent action, for example climate change.

"We're still in the middle of a big economic crisis and that pales into insignificance, compared to what the world is going to be like in a hundred years' time if we do not crack climate change. We won't need to worry about economic crises, we'll be struggling to live."

(Head of Financial Management)

A key element of the Agency's local programmatic was to be recognised as a best practice organisation in environmental management. This involved the development of management processes and practices that could be adopted by all organisations and the integration of business-like characteristics into their public service programmatic such as the "business case for sustainability" as part of their commitment to "practise what they preached".

The need for the Environment Agency to become more sustainable in all it did was recognised, but how this was implemented was mediated by their ability and authority to change. Specifically the Agency sought to demonstrate the feasibility of change to others, balanced with risks from the nexus of programmatic discourses. This led to an eco-efficiency bias in the elements of DEFRA (2005) that formed part of the Agency's strategic discourse.

\section{The selection and construction of sustainability mediating instruments}

The power and problems associated with accounting mediating instruments in organisational transformation, including sustainability, is well documented (e.g., Kurunmäki, 2004; Kurunmäki and Miller, 2006, 2011; Kurunmäki et al., 2003). Within the Agency the selection of "sustainable" mediating objects was influenced by the normal interaction among staff conducting their day-to-day work. All staff interviewed viewed ecoefficiency as part of their role as the guardian of the natural environment. The following quote from the Chief Executive Officer illustrated the justification of the use of accounting-sustainability hybrids to mediate between the sustainability programmatic, the Agency's strategy, local practice and staff motivation and values.

"Most of our staff believe that the reason we're doing a lot of our work is to improve the environment and therefore, by us doing this, we're helping directly, doing our bit for the environment. Second is that by being as green as we can be, we're setting an example for others and that makes it easier when we're going out and doing our work because quite often people will say 'Well what do you do and how are you doing it?', and they will copy us. And a third one is that by using less gas, by doing less mileage, you're saving money and that money can be reinvested...In a private organisation that would be profit, but for us it's reinvesting 
it in doing more work for the environment. So recycling stuff and reducing waste and making sure that money is used to good effect."

(Chief Executive Officer)

The selection of mediating instruments in the Environment Agency was affected by their widespread use of accounting-sustainability hybrids. The Agency has developed and used such hybrids since 1996 and environmental accounting (a form of accounting-sustainability hybrid) was considered normal practice throughout the Environment Agency, for example.

"Environmental monitoring and reporting is part of the Environment Agency's DNA. The Environment Agency is a special case in this context with high levels of knowhow continuously being developed."

(Head of Financial Management)

"Since the beginning of the Environment Agency, we've had carbon, waste and water usage data for internal management systems and have set targets on reducing and monitoring these things."

(Head of Environmental Finance)

The existence of local accounting-sustainability hybrids impacted on the perceived usefulness of non-local hybrids as mediating instruments between the sustainability programmatic and the Agency's activities. Within the Agency there was a specialist Environmental Finance Team whose function was to develop and implement best-practice accounting-sustainability hybrids. The Environmental Finance Team were considered the local experts in selecting appropriate mediating instruments.

Environmental Finance Team members described how their hybrids evolved through the systematic application of basic accounting concepts to the problem of reducing environmental impacts, and believed that accounting, if applied appropriately, could positively contribute to the sustainable development of organisations. Team members were committed to the evolution of accounting-sustainability hybrids that built incrementally on measurable successes and the gradual integration and normalisation of the more radical elements of the sustainability programmatic. The ability of non-local accounting-sustainability hybrids to fit into or enhance the existing hybridisation process was an important criterion as to whether it was adopted for mediating or governing in the Environment Agency.

Prior successes of the Agency's accounting-sustainability objects in mediating and defining common points of reference between the sustainability programmatic, organisational values, statutory responsibilities and the motivation of individual employees was already well established. For example:

"On the whole, we've tried to demonstrate there have been savings from doing this in terms of pounds savings and physical savings. So we're trying to link the two together, pounds and physical units; that's probably been the biggest success and 
the biggest heart-winner, heart and mind winner, because people can latch onto that, 'Ah, I can see the value of that now, I wondered why you've been doing that'."

(Regional Operations Director)

"It is a good thing to be able to understand what your environmental impacts are ... to be able to understand what it is costing you to be able to deliver benefit and know-how."

(Chief Executive Officer)

The existing level of expertise and general satisfaction of the Agency's senior management with the Environmental Finance Team's accounting-sustainability hybrids in mediating the sustainability programmatic meant that any non-local accounting-hybrid was subject to a high level of critical evaluation as to its fitness for purpose in the Agency.

Environment Agency accountants were active (often in leadership roles) in accounting networks, standard setting processes and policy forums, (e.g., the Association of Chartered Certified Accountants, Socially Responsible Pensions, Accounting for Sustainability, and HM Treasury's Financial Reporting Advisory Board ${ }^{9}$ ) and had an extensive knowledge of accounting-sustainability hybrids. The Agency ${ }^{10}$ was involved in the development of a number of such generic hybrids, including the Connected Reporting Framework. The developers of the Connected Reporting Framework claimed it was designed to link a holistic understanding of sustainability with the strategy and activities of an organisation, including social welfare, fair trade and lifecycle impacts of its products and services (Fries et al., 2010). However, the Environmental Finance Team selected their local hybrids in preference to the Connected Reporting Framework despite claims that it could be an effective sustainability mediating instrument. Team members were positive about the mediating role the Connected Reporting Framework could play in other organisations, but were ambivalent about its usefulness to the Environment Agency. The Connected Reporting Framework was described by one interviewee as "like putting on an old shoe". The following quotes illustrate their reaction to the Connected Reporting Framework.

"It [the Connected Reporting Framework] is another framework, it's got some aspects that we've done before, so let's take the good bits, let's use the bits that we were already going to do anyway and let's throw out the bits that we actually think don't work. I don't think we've radically changed what we've done."

(Environmental Finance Manager)

"Let's import what you know, so let's make this as sort of sensible and pragmatic as we can make it."

(Director of Finance)

\footnotetext{
${ }^{9}$ HM Treasury's Financial Reporting Advisory Board is the body responsible for setting public sector financial reporting standards in the UK.

${ }^{10}$ Not all of the Environmental Finance Team were involved in the initial development of the Connected Reporting Framework although they were involved in its piloting and adaptation for public sector reporting.
} 
"Our internal environmental management systems were much better developed than the actual reporting required for the Connected Reporting Framework."

(Head of Environmental Finance)

The Connected Reporting Framework was not considered to add significant value to the Agency over their existing accounting-sustainability objects, although it was credited with the re-invigoration of their external environmental reporting and internally legitimated their planned programme of accounting-sustainability hybridisation. Environmental Finance Team staff identified a number of technical deficiencies in the Connected Reporting Framework $^{11}$, but it was the Connected Reporting Framework's lack of fit with the Agency's everyday experiences that mitigated against its selection as a mediating instrument. However, Environmental Finance Team staff acknowledged that their assemblage of hybrids did not fully account for their sustainability impacts (positive or negative). For example the Environment Finance Manager stated that, "It [their system] is not sustainability reporting in the truest sense, it is environmental reporting."

This self-criticism was supported by the Chief Executive Officer who argued that they did not account for all their material environmental impacts or include the sustainability outcomes of their activities. The Connected Reporting Framework did incorporate more social concerns than the Environment Agency accountingsustainability hybrids, but this was insufficient to justify its adoption in the Agency. The Connected Reporting Framework could have mediated more elements of the sustainability programmatic to the Environment Agency yet it was not accepted as a plausible or generally understood mediating instrument. However, as will be discussed later, it also could have seriously disrupted the Environment Agency's more systematic approach to the hybridisation of accounting and sustainability.

The construction and embedding of accounting-sustainability hybrids into governing processes Accounting-sustainability hybridisation in the Environment Agency was a continual process that utilised the governing and mediation possibilities of different hybrids (similar to the findings of Briers and Chua, 2004; Miller and O'Leary, 1993, 1994; Miller et al., 2008). The Environmental Finance Team's objective was to create an effective assemblage of accounting-sustainability hybrids rather than to perfect individual techniques. The Team developed a pragmatic approach based on solving locally defined problems (such as the reduction of energy consumption). This involved developing accounting techniques, in conjunction with local experts, experimenting with different hybrids and reflecting on their effectiveness in answering specific local problems. They refined these hybrids until consensus emerged that they were effective in governing that problem and, where appropriate, integrated these hybrids into their normal accounting processes and practices. The Environmental Finance Team used the measurable success (and failures) of these new governing techniques to problematise other aspects of their activities and created new possibilities for change, similar to the iterative processes observed by Miller and O'Leary (1993, 1994). For example, the integration of office energy

\footnotetext{
${ }^{11}$ The Environment Agency successfully promoted a highly modified version of the Connected Reporting Framework to be included in the UK Public Sector Accounting Reporting Standards (UK Treasury, 2012). A full discussion of this process falls outside the scope of this paper.
} 
consumption data into their budgeting and performance measurement systems enabled more effective governance of their energy use in buildings, but the measurable success of this energy governance technique was also used to problematise the use of other resources in their buildings (such as paper, water and waste) and created possibilities of developing systems to govern and reduce the consumption of these resources. The accounting hybrids that successfully reduced water use and waste in Agency buildings were then used to evaluate other Agency activities in an attempt to identify further possibilities for water and waste reduction.

As these hybrids were normalised within the accounting system they also created the capacity to respond to new problems as they emerged, such as climate change. For example, the availability of energy consumption data for buildings and transportation combined with carbon conversion metrics allowed the Environment Agency to extend their energy governance system to a carbon governance system that channelled the climate change programmatic into all parts of the Agency that consumed energy.

A good example of how an individual accounting-sustainability hybrid fitted into the wider assemblage was the Agency's Low Carbon Staff Travel System. Over time the Environment Agency developed a set of staff travel practices and processes that merged expertise from a wide range of professions and disciplines. These included procurement, transport management, carbon management, air emissions, management and financial accounting, logistics, management controls and performance measurement. The Low Carbon Staff Travel System evolved into a set of decision protocols and metrics designed to reduce carbon emissions by prompting consideration of the need for travel and the selection of the lowest carbon option available. Figure 1 illustrates how the Low Carbon Staff Travel System was embedded within the Agency's management and accounting systems.

\section{Insert Figure 1 - The Connectivity of Low Carbon Staff Travel System within the Environment Agency (source} Georgakopoulos and Thomson, 2010, p.139)

The accounting processes and practices contained within the Low Carbon Staff Travel System were influential in making visible both the costs and carbon impacts of staff travel choices and legitimated low carbon travel practices through the calculation of cost savings. Staff travel miles and costs of individual staff travel choices were captured in the Agency's financial ledger and formed part of the budgetary systems, corporate scorecards, key performance targets and internal benchmarking. The Low Carbon Staff Travel System was fully integrated into the Agency's accounting, management, procurement and investment practices and processes.

The success of the Low Carbon Staff Travel System was used by the Environmental Finance Team to problematise other climate change impacts of the Agency, including procurement and outcome measures. The Environmental Finance Team extended the principles of the Low Carbon Staff Travel System to evaluate the embedded (lifecycle) carbon in all goods and services purchased and the net lifecycle carbon emissions of their civil engineering programme, including the flood prevention infrastructure. The further development of 
lifecycle carbon accounting hybrids enabled the Environment Agency to make radical step-changes to reduce their impact on climate change and build the capacity to mediate with other aspects of the sustainability programmatic in their supply chain, such as human rights, fair trade, health and safety.

Contrary to prior research, accountants were attributed with helping the Agency become more sustainable. For example:

"Its [engagement with environment] opened up the finance team and they've become much more colleagues rather than gatekeepers. And I think our business is benefiting enormously in having what I call 'user-friendly accountants'."

(Chair of Audit Risk and Governance Committee)

In the literature review we noted that the calculability of "the other" was important in resisting or enhancing the development of most accounting hybrids, as well as accounting-sustainability hybrids (e.g., Maunders and Burritt, 1991; Georgakopoulos and Thomson, 2008.). We observed that calculative rationality, evidence and measurement formed a major part of the Agency's values and activities not just in the accounting department. Employees throughout the Environment Agency were highly knowledgeable about sustainability, the science underpinning their regulations and methods of calculating environmental impacts. Measuring the environment was normalised ${ }^{12}$ within the Agency and there was little resistance and considerable scope to further hybridise accounting with the measurable elements of sustainability that fell within the Agency's statutory remit. Elements of the environment were already calculatively captured by scientific methods and in regulatory instruments and therefore hybridising with accounting was not viewed as problematic by other disciplines in the Environment Agency.

How effectively the accounting-sustainability hybrids translate the sustainability programmatic into local governing processes

In this section we analyse how effectively the Environment Agency's organisational accounting-sustainability hybrids translated the sustainability programmatic into their local governing processes. In particular we evaluate the potential of the Agency's hybrids to govern the sustainable transformations contained in DEFRA (2005). We also consider whether these accounting-sustainability hybrids could distort the embedding of the sustainability programmatic in the Environment Agency. We analyse the Agency's hybrids in order to establish whether they problematised their unsustainable actions, supported decisions to promote sustainable change or focussed on the limited eco-efficiency concerns commonly found in "for-profit" organisations.

\footnotetext{
${ }^{12}$ For example, acceptable air emissions in urban areas are defined in terms of specific pollutants such as lead, nitrous-oxide, carbon monoxide and by specific measures, for example, lead emissions. The latter are problematic if they exceed 0.5 micrograms per cubic metre or less, when expressed as an annual mean.
} 
We identified a wide range of individual accounting-sustainability hybrids that operated in the Environment Agency, which are summarised in Table 2. These hybrid practices were mostly concerned with the establishment of the financial benefits of adopting eco-efficient practices and the problematisation of poor eco-housekeeping. Accounting-sustainability hybrids have been effective in embedding an eco-efficiency programmatic throughout the Agency, for example in their Low Carbon Staff Travel Protocol; but have been largely ineffective in areas such as social justice or community building.

\section{Table 2 about here}

A number of the Environment Agency's hybrids could be considered to be underpinned with a concern for ecoeffectiveness rather than eco-efficiency (Table 2, third column). Eco-effective accounting-sustainability hybrids with their emphasis on more system level changes have much greater potential to govern transformation along a sustainable trajectory. However, as mentioned earlier, there were a number of constraints on the ability of the Agency to transform sustainably, but there was evidence that they were building in-house capacity to enable future changes. This included working with suppliers to provide physical quantities on invoices, requiring suppliers to provide carbon calculations, the incorporation of physical measures in their ledger, the capture of resource usage in expense forms or department returns, environmental specifications in procurement processes, building environmental impacts into capital expenditure analysis, as well as training accounting staff in environmental management.

The Agency's assemblage of accounting-sustainability hybrids has the potential to problematise the ecoinefficiency and eco-ineffectiveness of its actions. This assemblage was used to systematically support ecoefficiency initiatives throughout the Environment Agency and to make substantive progress on the development of viable eco-effective hybrids.

\section{Key findings and insights from accounting-sustainability hybridisation in the Environment Agency}

The accounting-sustainability hybridisation processes in the Environment Agency did not follow a "non-local to local" trajectory, but were more complex with strong "local to non-local" and "local to local" dynamics. Hybridisation in the Agency was driven by strong, cooperative intra-organisational dynamics framed by local accounting practices, partially decoupled from the sustainability programmatic but influenced by the wider set of programmatic discourses associated with UK public service organisations.

Within the Agency there was a widely held belief that accounting-sustainability hybrids could assist organisations develop sustainably. This belief was based on the cumulative, measurable environmental and financial benefits attributed to (and measured by) their hybrids. These included significant environmental improvements in carbon emissions, resource use, energy use, water use and waste produced (Thomson and Georgakopoulos, 2010). These improvements were not attributed to any single hybrid but to the systematic 
nature of their hybridisation process and the synergistic impact of their evolving assemblage of accountingsustainability hybrids.

When viewed from the perspective of developing such an assemblage of hybrids we observed the emergence of a positive sequence of transformations where individual accounting-sustainability objects both governed specific organisational problems and priorities and allowed for the creation of new possibilities of change through local mediation. However, we also recognise that the Environment Agency may be a special case in relation to accounting-sustainability hybridisation. They have considerable expertise in sustainability; there was no substantive conflict between their activities and the sustainability programmatic; they were assigned resources and the responsibilities to develop sustainability; they had power over others on environmental issues; they were underpinned by a calculative culture; their staff were committed to environmental governance; the measurement and calculation of the environment was normalised; their accounting staff were acknowledged leaders in the field; and, engagement with accountants in the Agency was welcomed. Environment Agency accountants were aware that the Agency's assemblage of accounting-sustainability hybrids was far from complete and recognised that there was an urgent need to develop accounting practices and processes to make visible and render governable the sustainable outcomes of their actions. In particular, the accountants were keen to move beyond eco-efficiency and develop eco-effective accounting-sustainability hybrids.

Most of the obstacles to the development of hybrids that were found to exist in other organisations did not exist in the Environment Agency and this perhaps explains our positive evaluation of the future potential of their hybrids. Our analysis of the Agency confirms many of the criticisms of past researchers into the role of accounting on sustainability transformation but also identifies a number of important insights that could inform the development of more effective organisational assemblages of accounting-sustainability hybrids.

The next section presents our analysis of the role of accounting in the shaping of sustainability practices in West Sussex County Council. West Sussex County Council shared with the Environment Agency a high level commitment to embedding sustainability throughout its activities but, as mentioned earlier, its regulatory remit in relation to the sustainability programmatic was very different. The following section will follow the same structure as the Environment Agency, which allows a holistic evaluation of hybridisation in the Council and facilitates comparison between the two cases.

\section{Accounting-Sustainability Hybridisation: West Sussex County Council}

The interpretation, prioritisation and construction of the local programmatic discourse 
Interviews with key representatives from the County Council Cabinet and Chief Executive's Board, as well as respondents from the Sustainability Group ${ }^{13}$, revealed a nexus of programmatic discourses impacting on accounting-sustainability hybridisation. As implied in the literature (for example, Van Helden et al., 2010), the UK Sustainable Development Strategy (DEFRA, 2005) was hybridised with other discourses, acting as a filter on activity at the Sustainability Group level and throughout West Sussex County Council.

While respecting the guiding principles and shared priorities for UK action contained in the UK Sustainable Development Strategy (DEFRA, 2005), it was clear from the Chief Executive Officer and Cabinet Member for Finance and Resources that these were viewed as a snapshot in a moving trajectory. The Cabinet Member, for example, pointed to improving upon A Time for Action: A Strategy for a Sustainable West Sussex (West Sussex Sustainability Forum, 2005), a two-page document translating the UK Sustainable Development Strategy (DEFRA, 2005) to West Sussex: "We had A Time for Action which was the sustainable strategy. But I felt we could do a lot more and wanted to take it further." In part, this attitude may be attributed to the prior positions held by these Board members requiring knowledge of the importance of environmental protection and sustainability. The Chief Executive Officer previously held office as the County's Director for Environment and Development, and the Cabinet Member for Finance and Resources had previously been responsible for the Environment and Economy. The Chief Executive Officer had been involved in the 1992 Rio Climate Change Convention negotiations, suggesting both familiarity with the foundations of the UK Sustainable Development Strategy (DEFRA, 2005) and the fluid nature of debates on sustainability.

Notwithstanding the above, the UK Sustainable Development Strategy (DEFRA, 2005) was broadly interpreted as requiring changes in the Council's decision making processes. The Cabinet Member presented the Council's approach to sustainability as " $360^{\circ}$ vision, $360^{\circ}$ thinking and $360^{\circ}$ of sustainability". The $360^{\circ}$ vision, a catch-all phrase, incorporates the pursuit of an innovative and productive economy, a strong, healthy and just society, and a protected physical and natural environment, which is consistent with the goals for UK Government and Devolved Administrations included in DEFRA (2005). Decision-making practices in West Sussex County Council could be seen to depart from these goals as they encouraged consideration of environmental and social issues alongside financial issues rather than integrated as evoked in the UK Sustainable Development Strategy.

The sustainability programmatic as presented in the UK Sustainable Development Strategy (DEFRA, 2005) was further hybridised from two other main sources. Firstly, the discourse was "up-dated" with the expert knowledge of leading political activists. Here, the Cabinet Member revealed the influence of inspirational master classes hosted by the Council and delivered by Professor Jonathon Porritt (June 2006) and Lord Nicholas Stern (June 2008). The choice of experts in the political domain rather than the scientific field played

\footnotetext{
${ }^{13}$ The Sustainability Group is a small designated specialist unit of four workers charged with championing sustainability and directing efforts towards integrating sustainability into the everyday activities of West Sussex County Council.
} 
a part in swaying the agenda towards influencing behaviour more readily than concentrating on precise measurement and calculation (Ascui and Lovell, 2011).

The master classes held more resonance with the Cabinet Member than A Time for Action: A Strategy for a Sustainable West Sussex (West Sussex Sustainability Forum, 2005). The content of the transcript of the seminar on "Adapting to Change" delivered by Lord Stern clearly spells the risk of non-action on production and consumption in terms of temperature increases; highlights responsibility at the individual level by making explicit links from activities to climate change; and, has a practical orientation in drawing attention to targets on emissions on a per capita basis. In contrast, the Council's strategy refers to a number of key threats to the quality of life; positions itself on collective as well as individual action; and, is generic on achievement across the three spheres of sustainable development.

The influence of political activists, in conjunction with the passion for and sensitivity to environmental issues by key representatives of the Board, contributed towards a bias to action on climate change. The Chief Executive Officer commented on reducing carbon emissions:

"[It] has become such a totemic issue around the environment and sustainability. Things like the Stern Report have conquered the economic Everest on this. The underpinning for being able to tackle sustainability on those sorts of issues in economic and environment terms is now so strong it's sort of irresistible."

Social issues, in contrast, were perceived as diffuse and, by implication, difficult to get to grips with:

"That [social issues] is the $\$ 64,000$ question. And that's partly I think why in the last sort of seventeen years since Rio, it's not embedded in the same way. The social aspects, the community and cohesion aspects of sustainability have sort of been second runners in this."

\section{(Chief Executive Officer)}

Secondly, and more pervasively, the programmatic was hybridised with the government's new public management/efficiency/austerity programmatic discourses. As the Chief Executive officer explained: “I'm afraid money is such a central priority at the moment, it takes most of my time."

The new public management/efficiency/austerity programmatic overshadowed the sustainability programmatic and held greater "political potency" for the Board, leading to short-term economic interests prevailing over longer-term environmental concerns (Boston and Lempp, 2011) and consigning sustainable development as a secondary consideration within the organisation as a whole. As a result, environmental considerations were mostly framed by the more economic discourses put forth by government. 
The programmatic discourse was hybridised with the arguments of political activists in order to engage individual members of staff and yet was permeated by the UK Government's economic programmatics. An example of this was the lack of reference by interviewees to, say, Strong and Prosperous Communities (DCLG, 2006), implying that equivalent pressures were not felt in the social arena.

\section{The selection and construction of sustainability mediating instruments}

From the mediating instruments available for channelling the sustainability programmatic and achieving organisational transformation, the Council selected Forum for the Future's (2010) Sustainability Standard ${ }^{14}$ and the Connected Reporting Framework. These were described by a number of organisational participants as compatible with each other.

On the one hand, the Sustainability Standard was used by Council Members and Senior Officers to mobilise action across staffing groups. There was recognition by the Cabinet Member and Chief Executive Officer that sustainability champions alone were insufficient in driving organisational transformation, particularly if sustainability was to be viewed as a routine part of work roles. The Sustainability Standard helped in offering a benchmark matrix as a means for undertaking a self-assessment and providing a score mirroring those used by the Audit Commission in the Comprehensive Performance Assessment ${ }^{15}$. As a consequence, the weak to fair rating ("not awful but not great") held resonance with members of staff and signalled a need for improvement. The Sustainability Standard also helped in providing steps to mainstreaming sustainability in a local government context.

On the other hand, the Connected Reporting Framework was used to add momentum to a prior decision to integrate sustainability more widely in the Council. As articulated by the Chief Executive Officer:

"...it seemed to us that the whole project and the whole reporting framework were going to provide the impetus for a coherent and holistic approach to what our footprint was environmentally across a whole range of issues. So this seemed to offer the way forward for us to make a single commitment that would have a multiple impact, if you like. So rather than on each occasion when we looked at a new building or on each occasion at a new policy or whatever, trying to start the whole argumentation again, we made a single corporate commitment to achieving greater sustainability."

Although the Connected Reporting Framework was perceived as legitimising organisational commitment to sustainability, the Council retained agency on how the framework hybridised with their existing organisational processes and practices. In other words, the Sustainability Group did not legitimise the general orientation of

\footnotetext{
${ }^{14}$ The Sustainability Standard was developed by Forum for the Future and its local authority partners and is intended to encourage continuous improvement toward sustainable development through suggesting practical steps for the achievement of desired outcomes.

15 The Comprehensive Performance Assessment used an audit and inspection framework to determine an understandable benchmark rating of the performance of councils as well as identify areas for improvement on delivery of services to the public.
} 
the generic Connected Reporting Framework or, indeed, the use of the Accounting for Sustainability decisionmaking tool (see Spence and Rinaldi, in press) to ensure sustainability factors were taken into account. This is pertinent as the tool has the potential to render many of West Sussex County Council's service delivery imperatives visible, such as community building, community engagement and social justice. The Council's programmatic hybridisation and local programmatic discourse had the effect of imposing structural constraints upon the implementation of the Connected Reporting Framework. In addition, the Sustainability Group Manager revealed a hybrid "business case" Connected Reporting Framework in framing initiatives:

"A lot of people go on about sustainability; they take the three core areas now: social, environmental and economic impacts. But what we're trying to do is take those three areas and then that is surrounded by finance."

(Sustainability Group Manager)

The Connected Reporting Framework, as presented by the Accounting for Sustainability project, lay outside the Council's points of reference and, accordingly, was narrowed in focus when used as part of their sustainability reform process.

Consistent with the interpretation and perceived technical aspect of the Connected Reporting Framework, it was seen as a means of securing more involvement from the accountants in the Council's sustainability journey. As expressed by the Sustainability Group Manager, the input of accountants was critical: "So we can do sustainability, but where's the finance people? And they're the main people that you need to take forward sustainability."

A "business case" Connected Reporting Framework was in keeping with the hybrid discourse of advancing sustainability in a period of reducing resources. The Council undertook a Fundamental Service Review of all activities following a series of poor financial settlements coupled with minimal government grant increases and a pledge to keep Council Tax affordable. Specifically, the Council was charged with identifying efficiency savings to a total value of fifty million pounds sterling. As a consequence, the Sustainability Group Manager was keen to demonstrate positive economic and environmental benefits in the improvement of ecohousekeeping within the Council.

In order to further induce the involvement of accountants, members of the Sustainability Group used their prior knowledge of accounting processes and practices to demonstrate the financial benefits of their initiatives. In this way, the Sustainability Group reasoned that identifying financial savings from their initiatives would be sufficient in convincing accountants in the Council to support and further develop these accountingsustainability hybrids.

As shown, the Council selected Forum for the Future's Sustainability Standard and Connected Reporting Framework to add impetus to the sustainability agenda and help engage with staff. The Sustainability Group 
adapted the Connected Reporting Framework with the effect of compromising on some of the objectives as asserted by Accounting for Sustainability (Hopwood et al., 2010). Positive environmental and economic impacts were actively sought while positive impacts on society and social cohesion were assumed to occur on fulfilment of the changes in the other two spheres. The accountants, if not silent, assumed a supporting role in the implementation of the Connected Reporting Framework.

\section{The construction and embedding of accounting-sustainability hybrids into governing processes}

At local level, the Sustainability Group developed three accounting-sustainability hybrids (Sustainability Workplace Tool, Sustainability Appraisal and Carbon Model) that drew upon their accounting expertise, processes and practices (Grubnic and Owen, 2010). Development of these accounting-sustainability hybrids, and to varying degrees, their use in organisational governing, relied upon top level managerial and political support as well as internal and external networks.

Given the breadth of the sustainability programmatic discourse, the Sustainability Group Manager assigned one team member to lead on the construction of each accounting-sustainability hybrid. The group members were well versed in the hybridised local sustainability discourse although, generally, less familiar with the realities of practices inherent in an organisation responsible for the delivery of a diverse range of services. Work on the hybrids offered team members the opportunity of becoming more knowledgeable on current and incoming legislation, managerial regimes within the Council, publicly available strategic documents and political plans. Accordingly, Sustainability Officers located hybrids in government directives in addition to governing processes of the Cabinet and Chief Executive's Board.

The construction of the accounting-sustainability hybrids varied in terms of approach taken. When developing the Sustainability Workplace Tool and Sustainability Appraisal the staff started with external best practice exemplars and tailored them to their local needs. In the case of the Carbon Model they used a process of experimentation building on local know-how and experience. The Chief Executive Officer and Sustainability Group Manager were not adverse to using ideas developed elsewhere:

"We certainly have no difficulty with the notion that other people are doing things that we'd quite like to steal."

(Chief Executive Officer)

"We always try and use tools that are currently the best practice in the market." (Sustainability Group Manager)

Seeking practices established in another location can be linked to a lack of human resources within the Group and a desire to promote behavioural change sooner rather than later. The Sustainability Appraisal, for example, was based on the Integrated Appraisal Toolkit for the North West (NWRA, 2003) and, specifically, the idea that the sustainability of projects can more readily be shaped at the initial scoping stage. The North-West Toolkit had the added benefit of refinement subsequent to an extensive consultation exercise with bodies 
such as the Health Development Agency and Environment Agency. The lead worker on the Sustainability Appraisal focussed her work on incorporating objectives from the West Sussex Sustainable Community Strategy (WSSC, 2009a) into this local accounting-sustainability hybrid in order to ensure relevance to in-house projects.

The Sustainability Appraisal and, to a greater extent, the Sustainability Workplace Tool, included assessments designed to ensure more eco-efficient practices. As an example, the Sustainability Workplace Tool sought to promote energy reduction practices among members of staff such as the unplugging of computer terminals at the end of a working day. In this way, the hybrids collectively focussed on reducing negative environmental consequences and, with particular reference to the Sustainable Workplace Tool, largely ignored the sustainable consequences of services delivered.

The experimental approach undertaken in developing the Carbon Model both utilised and extended the knowledge of the Climate Change Officer. The Officer justified experimentation on the basis of general recommendations submitted by a group of consultants including the need for "financial innovation" within the Council. For the development of this hybrid, innovation was greatly facilitated through access to extensive documentation generated by the Fundamental Service Review. This incorporated diagrammatic depictions of processes integral to delivering services. The Officer also secured cooperation and substantial input from two senior managers with responsibilities for two distinct areas (road maintenance and residential site management). In this way, the hybrid was tailored to the local setting and services delivered.

Similar to the Sustainability Workplace Tool and Sustainability Appraisal, the Carbon Model was justified on the basis of local service imperatives. As the Climate Change Officer articulated:

"We can't afford not to do something about our carbon emissions. Reducing our
emissions will not only reduce the negative effect we have on climate change, but
by reducing our energy bills, we will also save the County Council large amounts of
money."

(WSCC, Sustainability Report 2007)

However, in mediating between the need for eco-efficiency on the one hand and compliance to national indicators on the other, the Officer envisioned the Carbon Model as promoting social gain. Information generated by the model permitted the Climate Change Officer in conjunction with the Service Manager/Owner to contemplate the restructuring of services such that social outcomes would be achieved.

The Carbon Model, as a technical tool, encompassed both carbon dioxide emissions arising from service delivery lines and financial values relating to energy usage. Using diagrams on service processes, the Climate Change Officer, with some reliance on the expertise of the senior managers, mapped energy relating to accommodating staff; travel; off-grid fuels (such as diesel and propane); and, contractors. Data for the Carbon 
Model was then derived from annual electricity and gas bills, an internal team focussed exclusively on transport ("anything in terms of transport, it will be under a cost code") and contractors. Similar to activitybased costing, the Climate Change Officer designed the Model in a way to enable service managers to identify and remove non-value adding energy units and costs.

In contrast to the Carbon Model, the Sustainability Workplace Tool and Sustainability Appraisal, at the time of research, did not incorporate measurements in the form of financial savings. Rather, these accountingsustainability hybrids were developed on the assumption that savings would accrue from changing behaviour. In a newsletter placed on the intranet, the Sustainability Group argued: "The Carbon Trust suggests that at least $10 \%$ of all energy costs can be reduced by improving staff behaviour". However, there was evidence of secondary hybridisation in rendering visible the cost of poor resource management in the future.

Governing with the Sustainability Workplace Tool required subjective judgements rather than more precise measurements. Lacking accounting input, internal legitimacy was attempted by assigning a Staff Sustainability Group Member to manage the use of the Sustainability Workplace Tool. This involved an assessment of six areas (waste, energy, procurement, water, people and transport) for an individual department, team or building, which generated a percentage score, and a requirement to improve that score by at least five percentage points the following year.

Both the Sustainability Workplace Tool and Sustainability Appraisal used a traffic light system to show results. As with Forum for the Future's Sustainability Standard, this held more resonance with staff members, highlighting areas requiring attention. Partly reflecting its stage of development, the Carbon Model relied to a greater extent on the close interaction between the Climate Change Officer and respective service managers to better understand local service provision in order to effect change.

The Council had a small but dedicated resource for developing accounting-sustainability hybrids. At one end of the scale, the Sustainability Workplace Tool encompassed eco-housekeeping measures applicable to all staff groupings. Because of its generic nature, the hybrid did not infringe upon regulatory regimes imposed by Central Government or necessarily require changes to service delivery beyond exercising thrift. At the other end of the scale, application of the Carbon Model demonstrated potential in promoting change of a more transformational nature. The hybrid was designed to reveal unknowns in terms of energy consumption and, furthermore, prompt discussions on how to improve service delivery including social outcomes.

How effectively the accounting-sustainability hybrids translate the sustainability programmatic into local governing processes

As with the Environment Agency, accounting-sustainability hybrids were effective in translating eco-efficiency in relation to Council activities into their local governing processes and recognising the importance of ecoeffectiveness. The Sustainability Group sought to contribute to social justice directly through implementation 
of the Sustainability Appraisal and, indirectly, through the embedding and piloting of the Sustainable Workplace Tool and Carbon Model.

Members of the Sustainability Group had heightened awareness of the need for eco-effectiveness and, consistent with the messages of Lord Stern, regarded the management of environmental risks as a local imperative. As a result, all three local accounting-sustainability hybrids sought to reduce energy use and, in so doing, contain carbon dioxide emissions. Metrics following completion of the Sustainable Workplace Tool were collated at directorate level and improvement targets monitored via incorporation in the Corporate Sustainability Programme 2009-2013 (WSCC, 2009b).

As a pre-requisite to formal tracking, the hybrids had the backing of the County Council Cabinet and Chief Executive's Board in the expressed ambition of getting their "own house" in order as well as providing leadership and direction to other public service organisations and the surrounding local community. As the Chief Executive Officer expressed:

"There's two real issues on that; one is the environmental footprint of the organisation as an organisation and the other, and much broader answer, is around policy and other leads. [What] does the County Council give West Sussex as community leaders, as the providers of $80 \%$ of local government services? [What does it provide] to others, to pursue more sustainable approaches?"

In a complementary move to focus attention on the importance of climate protection, and counter potential resistance, interview respondents cited using "visible" examples such as how recent droughts impacted on local reservoirs as part of their governing processes.

Eco-effectiveness was assumed by the Sustainability Group to be linked to eco-efficiency in that better housekeeping measures incorporated into the hybrids would result in the release of "financial dividends". Although there were targets on more parsimonious use of resources, the Sustainability Group Manager admitted to work needed on quantifying financial savings. For example, he suggested dual hybridisation of accounting in developing increased understanding of whole-life costing and lifecycle assessment. However, one by-product of non-inclusion of calculable savings in the Sustainable Workplace Tool was the promotion of respect for the environment and, moreover, operation within environmental limits as a worthy journey in its own right among staff members.

The Sustainability Group as a conduit for the Chief Executive's Board sought to contribute directly and, more so, indirectly, to the achievement of social outcomes. The Sustainability Appraisal, for example, in line with the articulated $360^{\circ}$ vision, attempted to include social concerns when reviewing new project proposals. Nevertheless, it is fair to say that managing environmental and economic risks consumed most of the effort of this Group, as reflected in the general orientation of the hybrids and the content of the Corporate Sustainability Programme 2009-2013 (WSCC, 2009b). Social commitments in the latter were confined to 
equality of employment within the Council, increasing numbers of staff engaged in community volunteering and reducing workplace bullying.

Given the above, it would be incorrect to infer that issues such as creating safer and stronger communities, improving the quality of life of older people and children, young people and families as risk, promoting healthier communities and raising standards across schools, identified in the UK Sustainable Development Strategy (DEFRA, 2005) as within the remit of local government, were not attended to by the Council. Indeed, the Council recently underwent a restructuring of the Chief Executive Board in order to promote a unified team assuming responsibilities across the social spectrum of the sustainability programmatic. Following on, social imperatives were viewed as main council business, with all professional enclosures and staff groupings responsible for realising county strategy.

As argued by the Sustainability Group Manager, development and implementation of accounting-sustainability hybrids contributed to the maintenance of front-line services and, therefore, indirectly, current social outcomes. To make his point, the Manager cited the tracking of expenditure on energy and water over an eight-year period, with exponential growth revealing consequences on Council budgets. Crudely, the line of reasoning undertaken followed the logic of environment plus finance equals the protection of core "social" services. As rationalised by him: "We keep saying, if you want to keep paying [major energy supply company] money, fine, but I'd rather pay our child protection officers money."

In summary, the local accounting-sustainability hybrids practiced by the Sustainability Group centred on the more recently identified environmental risks and sustainable consumption of resources in order to safeguard the planet as well as Council funds. When evaluated against the sustainability programmatic, lack of further inclusion of social issues into the hybrids constituted a missing link between the social, economic and environmental. As a result, a deeper understanding of commonalities among elements, as well as risks and uncertainties following trade-offs, was foregone.

\section{Key findings and insights from accounting-sustainability hybridisation in West Sussex County Council.}

The accounting-sustainability hybridisation processes in the West Sussex County Council, similar to that observed in the Environment Agency, exhibited a range of different trajectories including some "non-local to local" and relatively strong "local to local" and "local to non-local" dynamics. Accounting-sustainability hybridisation was driven from the top of the Council and operationalised via the Sustainability Group rather than from the mainstream accounting function. The hybridisation processes was affected by a nexus of programmatic discourses affecting the UK public sector and in particular by the new public management and austerity discourses. Despite the clear commitment to sustainability reform the sustainability programmatic was perceived as relatively weak in a context of increasing service delivery imperatives and poor financial settlements. 
Similar to the findings of the Environment Agency, interview respondents within West Sussex County Council believed that accounting-sustainability hybrids could assist them in developing sustainably based on the cumulative, measurable environmental and financial benefits attributed to (and measured by) their assemblage of hybrids. However, unlike the Environment Agency the Council's assemblage of accountingsustainability hybrids remained distinct from the mainstream financial accounting processes and practices. These hybrids ran in parallel to the mainstream accounting systems providing greater visibility to the benefits of eco-efficiency initiatives. The Sustainability Group was active in trying to engage with the mainstream Council accountants in order that these accounting-sustainability hybrids would eventually become part of the mainstream accounting systems.

There was some evidence of a conflict between the potential implications of embedding sustainability and the financial settlements to the Council from Government impacting upon organisational budgets. This helps explain the emergence of a "business case" for sustainability, which concentrated on financially beneficial activities that did not substantively challenge everyday organisational activities. However, the Sustainability Group, working with very limited resources and outside the mainstream accounting function, was able to create a range of innovative accounting-sustainability hybrids and influence governing processes. The hybrids resulted in a significant improvement in the eco-efficiency of council operations and created a growing awareness of the importance of considering the Council's eco-effectiveness. Collectively, the hybrids created substantial potential for further local sustainability mediation and change.

The next section presents our concluding comments and a discussion of the main implications of our analysis of accounting-sustainability hybridisation in the Environment Agency and West Sussex County Council.

\section{Conclusion}

The main purpose of this paper was to explore the role of accounting-sustainability hybrids in shaping and reshaping sustainability practices. As part of this exploration, we developed a holistic framework from our review of the accounting, governmentality, public sector, sustainability and hybridisation literatures (for example, Gray, 2010; Kurunmäki and Miller, 2011; Miller et al, 2008; Wise, 1988). We used this to analyse the factors and processes that shaped the implementation of the UK Sustainable Development Strategy (DEFRA, 2005) in the Environment Agency and West Sussex County Council. Our analysis revealed a number of empirical insights into accounting-sustainability hybrids and led to the realisation that this holistic framework could be usefully applied in other studies that seek to investigate the complex interactions between accounting and sustainability. This framework enables a more in-depth understanding of accounting and sustainability hybridisation at a theoretical level as well as when analysing different empirical sites. It can also be of use to researchers and practitioners seeking to design and embed accounting-sustainability hybrids into local organisational settings that will enable, rather than constrain, sustainable transformations.

\section{Theoretical contributions}


We believe that our holistic framework further refines the insights offered by prior governmentality studies in helping to understand the relationship between accounting and organisational change. In addition to considering the dynamics from policy injunctions to the embedding of these ideals at local level (see Kurunmäki and Miller, 2011), we propose an iterative holistic approach. Our main theoretical contribution is in developing a more detailed exploration of how (or whether) accounting-sustainability hybrids are selected as mediating instruments and the impact of this selection process on the local embedding of the sustainability programmatic, as well as any further accounting-sustainability hybridisation. In particular the work of Wise $(1988,1995)$ and Wise and Smith (1989a, b, 1990) suggests that this selection process will be biased towards the existing everyday practices within an organisation and biased against more abstract, novel ideas at the programmatic level. This observation poses a number of questions as to the effectiveness of developing generic, non-local accounting-sustainability hybrids that draw mainly from the programmatic level, based on their governing potential.

Another theoretical contribution for future research is the distinction between the governing and mediating roles of specific accounting-sustainability hybrids. The governing potential of such a hybrid relates to its ability to manage a defined organisational risk, while the mediating potential relates to the hybrid's ability to channel aspects of the sustainability programmatic into other areas of the organisation (or beyond) as a precursor to further transformation. Past research (and developments in practice) has failed to adequately address this difference. The attributes of effective governance and effective mediation are different and therefore should not be conflated. From a theoretical perspective, there is a lack of explicit consideration as to how, in general, key actors select (and ignore) mediating instruments as legitimate at local level. This may partially explain the relatively low adoption of accounting-sustainability hybrids that reflect the non-eco-efficient aspects of the sustainability programmatic.

Our holistic framework allowed us to make a number of empirical contributions in response to a general call for more research on sustainability accounting in the public services (Ball and Grubnic, 2007; Ball et al., 2009) and to understand the complex inter-relationships between accounting, sustainability and local service delivery imperatives. Our analysis challenges the appropriateness of non-local 'for-profit' accountingsustainability hybrids for mediation and governance in regulatory-hybrid organisations (see for example Broadbent, et al., 2001; Kurunmäki et al., 2011; Miller et al, 2008), but also recognises the power of locally legitimate 'public sector' accounting-hybrids in promoting and restricting sustainable transformations.

We will now summarise the findings revealed through application of the holistic framework to our case studies. We also reflect on the power of the local in accounting-sustainability hybridisation, the lack of resistance from non-accounting staff, the normalisation of calculative capture of the environment and the transformative, governing and mediating potential of accounting-sustainability hybrids in the Environment Agency and West Sussex County Council. 
The interpretation, prioritisation and construction of the local programmatic discourse

Given that local hybrid programmatics are used to frame and legitimate any organisational transformation, understanding how they are constructed is critical to understanding the hybridisation of accounting and sustainability. We observe in both cases that the impact of the sustainability programmatic on the local strategic discourses of the Environment Agency and West Sussex County Council was diluted due to other programmatics such as new public management, public welfare, value for money, deregulation and competition, economic growth, and austerity. Elements of the sustainability programmatic are evident in the respective local strategic discourses, but typically relate to existing institutional responsibilities and resource constraints. The UK Sustainable Development Strategy (DEFRA, 2005) appeared to legitimate existing commitments to the sustainability programmatic rather than to transform it.

Our analysis suggests that the sustainability programmatic may not be a powerful driving force for change in relation to the influence of other programmatics thus supporting prior studies on the limited capacity of regulatory hybrid organisations on responding to voluntary programmatics such as sustainability, unless they are backed up with specific regulatory changes (e.g., Kurunmäki, 2004; Lapsley and Wright, 2004, Laughlin, 2007; Llewellyn and Northcott, 2005).

The selection and construction of sustainability mediating instruments

Both the Environment Agency and West Sussex County Council have accounting-sustainability hybrids tailored to their strategic priorities and service delivery imperatives. In both organisations these hybrids are considered to have been effective in reducing their negative environmental impacts. Particularly in the Environment Agency it was the success of "home-grown" hybrids that influenced their selection as mediating instruments. Our findings are consistent with prior research (for example, Broadbent and Guthrie, 2008; Wise, 1988, 1995) that the everyday power and presence of costs, finance and resource constraints in working practices helps the selection of accounting-sustainability hybrids as mediating instruments. These accounting-sustainability hybrids that were constructed and adapted to local priorities appear to create a legitimate, plausible conceptual link between eco-efficiency and improved service delivery outcomes. The findings appear to suggest that in the context of sustainability, local factors seem to be more powerful than the non-local. The preference to select the known and the mundane as mediating instruments, particularly when responding to novel programmatics (Wise, 1988), regardless of any perceived technical or conceptual superiority of the external "expert" solution, is an important insight into the development of accounting-sustainability hybrids. The power of the local context and importance of local actors in determining what they consider to be acceptable mediating instruments should not be under-estimated but does create a potential obstacle to programmatic led reforms.

The construction and embedding of accounting-sustainability hybrids into governing processes

The accounting-sustainability hybridisation processes in both cases exhibited most of the characteristics identified in accounting-sustainability, new public management accounting and management accounting 
hybridisation research (e.g., Ball and Grubnic, 2007; Ball et al., 2009; Kurunmäki et al., 2011; Miller et al., 2008). The accounting-sustainability hybrids in the Environment Agency and West Sussex County Council were formed (and reformed) in the intersections and repeated interactions among programmatic discourses, resource constraints, political priorities, local accounting practices, the organisation's legal responsibilities, accountability relationships, existing assemblage of governing practices, existing knowledge of the sustainability programmatic and everyday service delivery imperatives.

In both cases, the accounting-sustainability hybrids did restrict the points of common reference for hybridisation possibilities (Miller et al., 2008; Miller and O'Leary, 2007; Wise, 1988) by privileging what both organisations were already doing and their existing local programmatics. These hybrids did not reflect all of the possible intersections of the sustainability programmatic with the local service delivery responsibilities in the Environment Agency or West Sussex County Council and therefore could restrict the full implementation of the UK Sustainable Development Strategy (DEFRA, 2005).

Our findings are consistent with prior studies (e.g., Cleaver, 1989; Lenoir, 1988; Levallois, 2011; Wise, 1988) that stress the need for mutual acceptance and understanding of the legitimacy of any mediating instrument and the ability of a potential mediating instrument to offer plausible translations of other theories and practices into their domains. It would appear that one consequence of the accountingisation of the UK public sector (Ball and Grubnic, 2007; Ball et al., 2009; Kurunmäki and Miller, 2006, 2011) is the greater awareness and understanding of accounting throughout public sector organisations. The normalisation of accountingpublic service hybrids over a sustained period has led to accounting objects possessing many of the characteristics associated with mediating instruments and thus increasing their likelihood of being part of any programmatic led reform.

Non-accounting workers involved in the sustainability transformation initiatives appear to have welcomed the development of accounting-sustainability hybrids. The hybridisation of accounting with sustainability is seen to grant greater power and legitimacy to local initiatives and improve their eco-efficiency. Non-accounting staff appear either unaware or unconcerned with the problems identified in accounting-sustainability research studies, such as managerial capture, problematic calculative capture, lack of challenge to unsustainable business as usual assumptions, and the inability for accounting to incorporate unmeasurable aspects of sustainable development (e.g., Cooper, 1992; Cooper et al., 2005; Everett, 2004; Everett and Neu, 2000). This suggests a need for more effective engagement by the accounting research community with all disciplines involved in sustainability reforms, particularly given the lack of independent critiques of many generic nonlocal accounting-sustainability hybrids that claim to be effective sustainable mediating and governing technologies.

As noted earlier the calculability of "the other"' was not a major obstacle to developing accountingsustainability hybrids in these two cases. For example, measuring the environment was a common practice in 
the Environment Agency and those elements of the environment already calculatively captured offered a number of locally legitimate accounting-sustainability hybridisation possibilities. However, it was the combined impact of a number of different factors that led to a majority of hybrids being underpinned by eco-efficiency concerns.

We challenge other researchers to identify appropriate local measures of the sustainability programmatic in order to convince practicing accountants of the existence of acceptable measures of "the other" by "the other" and demonstrate how these measures can be integrated into accounting processes and practices. This allows the possibility of combining the calculative techniques with the contemporary power and legitimacy of accounting in organisational governance in the context of sustainable transformation. However, this has to be tempered in light of concerns raised that accounting practices problematically capture the sustainability programmatic and suppress fields of visibility, forms of knowledge and techniques of governing considered essential for any sustainable transformations (e.g., Maunders and Burritt, 1991; O’Dwyer, 2003b; Puxty 1991; Russell and Thomson, 2009).

How effectively the accounting-sustainability hybrids translate the sustainability programmatic into local governing processes

Accounting-sustainability hybridisation in the Environment Agency and West Sussex County Council involved patterns of complex and reflexive dynamics as suggested by our holistic framework. Accounting-sustainability hybrids were present in the construction of local programmatic discourses and used to mediate between local practices and the sustainability programmatic. The influence of local hybrids at all stages of the sustainability transformation could create a self-referential dynamic with all subsequent hybridisations dominated by accounting characteristics with the risk of decoupling local practices from the sustainability programmatic. Our analysis of the cases demonstrates that this multi-level involvement of accounting-sustainability hybrids was partially responsible for the predominance of accounting-eco-efficient hybrids although without these hybrids it would be less likely that the eco-efficiency improvements in the Environment Agency and West Sussex County Council would have occurred. For example, it was the everyday accounting-sustainability practices, rather than non-local accounting-sustainability hybrids such as the Connected Reporting Framework, that were selected as mediating instruments between the sustainability programmatic and local processes and practices. The construction of local hybrids as mediating instruments was seen to omit significant elements of the sustainability programmatic but, on a pragmatic level, they did facilitate local changes in relation to climate change impacts, energy use, resource use and waste reduction. Our analysis suggests that these hybrids allowed elements of the weak sustainability programmatic discourse to hybridise with more powerful discourses (e.g., new public management, austerity, and modernisation) thus enabling change in local organisational practices.

Key findings and insights from accounting-sustainability hybridisation 
Despite the public sector context of our case studies (Ball and Grubnic, 2007; Ball et al., 2009), it would appear that our findings on the content and nature of accounting-sustainability hybrids are largely consistent with research into for-profit and third sector organisations (Figge et al., 2002; Henri and Journeault, 2010; Herbohn, 2005; Fries et al., 2010), with a privileging of accounting-eco-efficiency hybrids associated with cost-effective "eco-housekeeping" activities (Ball and Grubnic, 2007) or regulatory compliance (Georgakopoulos and Thomson, 2005, 2008, 2012). Despite the regulatory responsibilities of the Environment Agency and West Sussex County Council, their hybrids tended not to encompass all aspects of the sustainability programmatic (DEFRA, 2005).

The assemblages of accounting-sustainability hybrids are only partial representations of the sustainability programmatic, and as a result they are unable to support systematic reforms along a sustainable trajectory (Russell and Thomson, 2009) and could distort the intentions of the sustainability programmatic. Currently, such hybrids are powerful governing and mediating instruments (Hopwood et al., 2010) in these two public service organisations, but they ignore significant elements of the sustainability programmatic. These accounting-sustainability hybrids privilege one, albeit important, aspect of this programmatic and appear under-developed in terms of enacting the radical social transformations contained in the UK Sustainable Development Strategy (DEFRA, 2005). However, the interviews in the Environment Agency and West Sussex County Council identify a desire to develop hybrids that are capable of making visible, calculable and governable social justice, community building, eco-effectiveness and eco-justice in order to support wider sustainable transformations. They identified a number of obstacles that are preventing them from moving beyond accounting for the negative environmental impacts of their existing service delivery imperatives. There does appear to be a programme of reforms that suggests a potential for breaking through the "greenbusiness" ceiling.

\section{Final thoughts and implications}

This paper raises a number of important insights into how and whether accounting can enact this more radical transformation and we identify a number of challenges for further research. This paper extends our understanding of how accounting practices structure, legitimate and constrain discourses around the governing of society and nature. We have attempted to highlight how accounting-sustainability hybrids could (mis)translate the sustainability programmatic and strip it of its radical vision and potentially relegate it to a footnote of the modern, neo-liberal programmatic. We believe that this may not be an inevitable consequence and we observe the emergence of hybrids with the potential to challenge and transform, particularly when we consider organisational assemblages of accounting-sustainability hybrids such as in the Environment Agency and West Sussex County Council.

Creating plausible accounting-sustainability mediating instruments grounded in local contexts yet reflecting the sustainability programmatic remains a challenge for the development of more effective accountingsustainability hybrids. Our findings support the arguments of others (e.g., Gray, 2010; Lehman, 2001) that 
researchers should develop hybrids by understanding the sustainability programmatic (political and scientific) in order to develop sustainability-accounting hybrids that support and facilitate sustainable transformation. There is a similar challenge for researchers to develop and disseminate the "sustainability case" for business rather than relying on the more restrictive "business case" for sustainability. 


\section{References}

Accounting for Sustainability; The Prince's Accounting for Sustainability Project (2007). Accounting for Sustainability Report, www.accountingforsustainability.org.

Armstrong, P. (1994). The influence of Michel Foucault on accounting research. Critical Perspectives on Accounting, 5, 25-55.

Armstrong, P. (2006). Ideology and the grammar of idealism: The caterpillar controversy revisited. Critical Perspectives on Accounting, 17, 529-548.

Ascui, F., \& Lovell, H. (2011). As frames collide: making sense of carbon accounting. Accounting, Auditing \& Accountability Journal, 24(8), 978-999.

Ball, A. (2002). Sustainability accounting in UK local government: An agenda for research. ACCA, Research Report 78. London: UK.

Ball, A. (2005). Environmental accounting and change in UK local government. Accounting, Auditing and Accountability Journal, 18(3), 346-373.

Ball, A. (2007). Environmental accounting as workplace activism. Critical Perspectives on Accounting, 18(7), 759-778.

Ball, A., \& Grubnic, S. (2007). Sustainability accounting and accountability in the public sector. In J. Unerman, J. Bebbington, \& O’Dwyer, B. (Eds.), Sustainability accounting and accountability (pp.243265) London: UK.

Ball, A., Mason, I., Grubnic, S., \& Hughes, P. (2009). The carbon neutral public sector: early developments and an urgent agenda for research. Public Management Review, 11(5), 575-600. Bebbington, J. (2010). Accounting for Sustainable Development Performance,( CIMA/Elsevier: London) Bebbington, J., \& Gray, R. (2001). An account of sustainability: failure, success and a reconceptualisation. Critical Perspectives on Accounting, 12, 557-587.

Bebbington, J., Gray, R., Hibbitt C., \& Kirk, E. (2001). Full cost accounting: an agenda for action (Association of Chartered Certified Accountants: London).

Bhimani, A. \& Soonawalla, K. (2010). Sustainability and Organizational Connectivity at HSBC. In A. Hopwood, J. Unerman, \& J. Fries (Eds.), Accounting for sustainability: practical insights (pp.173 - 188). UK: Earthscan.

Boston, J., \& Lempp, F. (2011). Climate change: explaining and solving the mismatch between scientific urgency and political inertia. Accounting, Auditing \& Accountability Journal, 24(8), 10001021.

Boyne, G. (2002). Public and Private Management What's the difference? Journal of Management Studies, 39(1), 97-122.

Briers, M. \& Chua, W. (2001). The role of actor-networks and boundary objects in management accounting change: A field study of an implementation of activity-based costing. Accounting, Organizations and Society, 26, 237-269.

Brigham, M., Kiosse, P. V. \& Otley, D. (2010). One AVIVA, Twice the Value: Connecting Sustainability at AVIVA plc. In A. Hopwood, J. Unerman, \& J. Fries (Eds.), Accounting for sustainability: practical insights 
(pp.191 - 209). UK: Earthscan.

Broadbent, J., \& Guthrie, J. (2008). Public sector to public services: 20 years of contextual accounting research. Accounting, Auditing and Accountability Journal, 21(4), 129-169.

Broadbent, J., \& Laughlin, R. (2002). Accounting choices: technical and political trade-offs and the UK private finance initiative. Accounting, Auditing and Accountability Journal, 15(5), 622-654.

Broadbent, J., \& Laughlin, R. (2005). Government concerns and tensions in accounting standardsetting: the case of accounting for the Private Finance Initiative in the UK. Accounting \& Business Research, 35(3), 207-228.

Broadbent, J., \& Laughlin, R. (2008). Identifying and controlling risk: the problem of uncertainty in private finance initiative in the UK National Health Service. Critical Perspectives on Accounting, 19(1), 40-78.

Broadbent, J., Jacobs, K., \& Laughlin, R. (2001). Organisational resistance strategies to unwanted accounting and finance changes: the case of general medical practice in the UK. Accounting, Auditing \& Accountability Journal, 14(5), 565-86.

Cleaver, K. (1989). Adam Smith on Astronomy. History of Science 27, 211-218.

Cooper, C. (1992). The Non and Nom of Accounting for (M)other Nature). Accounting, Auditing and Accountability Journal, 15(3), 16-39.

Cooper, C., Taylor, P., Smith, N., \& Catchpowle, L. (2005). A discussion of the political potential of social accounting. Critical Perspectives on Accounting, 16(7), 951-974.

DCLG (2006). Strong and Prosperous Communities: The Local Government White Paper. Norwich: Department for Communities and Local Government.

Dean, M. (1999). Governmentality: power and rule in modern society. London: Sage Publications.

Dean, M. (2007). Governing societies. Berkshire: Open University Press.

DEFRA (2005). Securing the future: delivering UK sustainable development strategy. London: Crown Copyright.

Dorrestijn, S. (2012). Technical Mediation and Subjectivation: Tracing and Extending Foucault's Philosophy of Technology. Philosophy and Technology, 25: 221-241.

Environment Agency (2006). The Environment Agency Corporate Strategy 2006-2011. The Environment Agency.

Environment Agency (2009). Creating a better place 2010-2015. The Environment Agency, Bristol, UK. Everett, J. (2004). Exploring (false) dualisms for environmental accounting praxis. Critical Perspectives on Accounting, 15(8), 1061-84.

Everett, J., \& Neu, D. (2000). Ecological modernization and the limits of environmental accounting? Accounting Forum, 24(1), 5-29.

Everett, J., Neu, D., \& Rahaman, A. S. (2007). Accounting and the global fight against corruption. Accounting, Organizations and Society, 32,513-542.

Executive Office of the President (2013). The President's Climate Action Plan. Washington: The White House. 
Ezzamel, M., Robson, K., Stapleton, P., \& McLean, C. (2007). Discourse and institutional change: 'Giving accounts' and accountability. Management Accounting Research 18, 150-171.

Figge, F., Hahn, T., Schaltegger, S., \& Wagner, M. (2002). The Sustainability Balanced Scorecard linking sustainability management to business strategy. Business Strategy and the Environment, 11, 269-284.

Fischer, M., \& Ferlie, E. (2013). Resisting hybridisation between modes of clinical risk management: Contradiction, contest, and the production of intractable conflict. Accounting, Organizations and Society, 38(1): 30-49.

Forum for the Future (2010) Stepping up: a framework for public sector leadership on sustainability. Forum for the Future, www.forumforthefuture.org.

Frame, B., \& Cavanagh, J. (2009). Experiences of sustainability assessment: An awkward adolescence. Accounting Forum, 33, 195-208.

Frame, B., \& O'Connor, M. (2010). Integrating valuation and deliberation: the purposes of sustainability assessment. Environment Science and Policy, in press.

Fries, J., McCulloch, K., \& Webster, W. (2010). The Prince's accounting for sustainability project: creating 21st decision making and reporting systems to respond to 21st century challenges and opportunities. In A. Hopwood, J. Unerman, \& J. Fries (Eds.), Accounting for sustainability: practical insights (pp.29 -45). UK: Earthscan.

Georgakopoulos G., \& Thomson I. (2005). Organic salmon farming: risk perceptions, decision heuristics and the absence of environmental accounting. Accounting Forum, 29, 49-75.

Georgakopoulos G., \& Thomson I. (2008). Social reporting, engagements, controversies and conflict in an arena context. Accounting Auditing \& Accountability Journal, 21(8), 1116-1143.

Georgakopoulos G., \& Thomson I. (2012). Risk Conflicts and Demands for Social and Environmental Accounting: An Empirical Study. In A. Lindgreen, P. Kotler, J. Vanhamme \& F. Maon (Eds.), A Stakeholder Approach to Corporate Social Responsibility; Pressures, Conflicts and Reconciliation (pp.141 - 164). Gower.

GRI. (2005). GRI Sector Supplement for Public Agencies. Global Reporting Initiative, www.globalreporting.org.

Gouldson, A., \& Bebbington, J. (2007). Corporations and the governance of environmental risk. Environment and Planning C: Government and Policy, 25(1), 4-20.

Gray, R. (1997). The silent practice of social accounting and corporate social reporting in companies. In Zadek et al. (Eds.) Building Corporate Accountability: Emerging Practices in Social and Ethical Accounting, Auditing and Reporting. Earthscan: London.

Gray, R. H. (2002). The social accounting project and accounting organizations and society privileging engagement, imaginings, new accountings and pragmatism over critique? Accounting, Organizations and Society, 27, 687-708.

Gray, R. H. (2010). Is accounting for sustainability actually accounting for sustainability...and how would we know? An exploration of narratives of organisations and the planet. Accounting, 
Organizations and Society, 35, 47-62.

Gray, R. H., Dey, C., Owen, D., Evans, R., \& Zadek, S. (1997). Struggling with the praxis of social accounting: Stakeholders, accountability, audits and procedures. Accounting, Auditing \& Accountability Journal, 10,325-364.

Gray, R., Walters, D., Bebbington, J. \& Thomson, I. (1995). The greening of enterprise: An exploration of the (non) role of environmental accounting and environmental accountants in organisational change. Critical Perspectives on Accounting, 6(3) 211-239.

Grubnic, S., \& Owen, D. (2010). A golden thread for embedding sustainability in a local government context: The case of West Sussex County Council. In A. Hopwood, J. Unerman, \& J. Fries (Eds.), Accounting for sustainability: practical insights (pp.95-128). UK: Earthscan.

Harte, G. \& Owen, D. (1987). Fighting de-industrialisation: The role of local government social audits. Accounting, Organizations and Society, 12(2), 123-141.

Henri, J.F., \& Journeault, M. (2010). Eco-control: The influence of management control systems on environmental and economic performance. Accounting, Organizations and Society, 35: 63-80. Herbohn, K. (2005). A full cost environmental accounting experiment. Accounting, Organizations and Society, 30(6), 519.

Hood, C. (1995). The 'new public management' in the 1980s: Variations on a theme. Accounting, Organisations and Society, 20(1), 93-109.

Hopwood, A. (1983). On trying to study accounting in the contexts in which it operates. Accounting, Organizations and Society, 8(2-3), 287-305.

Hopwood, A. (1987). The archaeology of accounting systems. Accounting, Organizations and Society, 12(3), 207-234.

Hopwood, A. (2009). Accounting and the Environment. Accounting, Organizations and Society, 34(3-4) 433-43.

Hopwood, A., Unerman, J., \& Fries J. (2010). Accounting for Sustainability: Practical Insights. London: Earthscan.

Hopwood, A.G. (1976). Accounting and Human Behavior. Englewood Cliffs, NJ: Prentice Hall. Hoskin, K., \& Macve, R. (1986). Accounting and the examination: A genealogy of disciplinary power. Accounting, Organizations and Society, 11(2), 105-136.

Hyndman, N., \& Connolly, C. (2001). Accruals accounting in the public sector: A road not always taken, Management Accounting Research, 22(1) 36-45.

Jones, M. (1996). Accounting for biodiversity: A pilot study. British Accounting Review, 1996, 28,281303.

Kaplan, R. and Norton, D. (1992). The Balanced Scorecard--Measures That Drive Performance. Harvard Business Review, 70, 71-79.

Kastenhofer, K., Bechtold, U., \& Wilfing, H. (2011). Sustaining sustainability science: The role of established inter-disciplines. Ecological Economics 70, 835-843.

Kornberger, M., \& Carter, C. (2010). Manufacturing competition: How accounting practices shape 
strategy making in cities. Accounting, Auditing \& Accountability Journal, 23, 325-349.

Kurunmäki, L., \& Miller, P. (2011). Regulatory hybrids: partnerships, budgeting and modernizing government. Management Accounting Research, 22(4), 220-241.

Kurunmäki, L. (2004). A hybrid profession: The acquisition of management accounting expertise by medical professionals. Accounting, Organizations and Society, 29 (3-4). pp. 327-347.

Kurunmäki, L., (1999). Professional vs financial capital in the field of health care-struggles for the redistribution of power and control. Accounting, Organizations and Society, 24, 95-124.

Kurunmäki, L., Lapsley, I., \& Miller, P. (2011). Guest editorial: accounting within and beyond the state. Management Accounting Research, 22(4), 220-241.

Kurunmäki, L., Miller, P. (2006). Modernising government: the calculating self, hybridisation and performance measurement. Financial Accountability \& Management 22 (1), 87-106.

Kurunmäki, L., Melia, K. \& Lapsley, I. (2003). Accountingisation v legitimation: A comparative study of the use of accounting information in intensive care. Management Accounting Research, 14(2), 112139.

Lambert, C., \& Pezet, E. (2010). The making of the management accountant - becoming the producer of truthful knowledge. Accounting, Organizations and Society 35, 10-30.

Lapsley, I., \& Wright, E. (2004). The diffusion of management accounting innovations in the public sector: A research agenda. Management Accounting Research 15, 355-374.

Larrinaga-Gonzalez, C., \& Bebbington, J. (2001). Accounting change or institutional appropriation? - A case study of the implementation of environmental accounting. Critical Perspectives on Accounting,

$12,269-292$.

Laughlin, R. (2007).Critical reflections on research approaches, accounting regulation and the regulation of accounting. British Accounting Review, 39, 271-289.

Lehman, G. (2001). Reclaiming the public sphere: problems and prospects for corporate social and environmental accounting. Critical Perspectives on Accounting, 12, 713-733.

Lenoir, T. (1988). Practice, Reason, Context: The dialogue between theory and experiment. Science in Context, 2 (1) 3-22.

Levallois, C. (2011). Why were biological analogies in economics 'a bad thing'? Edith Penrose's Battles against social Darwinism and McCarthyism. Science in Context, 24(4) 465-485.

Lewis L. \& Ferguson D. (2010). Using the Connected Reporting Framework as a Driver of Change within EDF Energy. In A. Hopwood, J. Unerman, \& J. Fries (Eds.), Accounting for sustainability: practical insights (pp.73 - 89). UK: Earthscan.

Llewellyn S., \& Northcott, D. (2005). The average hospital. Accounting, Organizations and Society, 30, 555-583.

Llewellyn, S. (1994). Managing the boundary: How accounting is implicated in maintaining the organization. Accounting, Auditing and Accountability Journal, 7(4), 4-23.

Lohman, L. (2009). Towards a different debate in environmental accounting: The case of carbon and cost benefit. Accounting, Organizations and Society, 34(3-4), 499-534. 
MacKenzie, D. (2009). Making things the same: Gases, emission rights and the politics of carbon markets. Accounting, Organizations and Society, 34(3-4), 440-455.

Maunders, K., T., \& Burritt, R., L. (1991). Accounting and Ecological Crisis. Accounting, Auditing and Accountability Journal, 4(3), 9-26.

McKinlay, A., Carter, C., Pezet, E., \& Clegg, S. (2010). Using Foucault to make strategy. Accounting, Auditing \& Accountability Journal, 23, 1012-1031.

Mennicken, A. (2008). Connecting worlds: The translation of international auditing standards into Post-Soviet audit practice. Accounting, Organizations and Society 33 (4/5), 384-414.

Miller, P., \& O'Leary, T. (1987). Accounting and the construction of governable person. Accounting, Organizations and Society, 12(3), 235-265.

Miller, P., \& O'Leary, T. (1993). Accounting expertise and the politics of the product: Economic citizenship and modes of corporate governance. Accounting, Organizations and Society, 18 (2/3), 187206.

Miller, P., \& O'Leary, T. (1994). Accounting, "economic citizenship" and the spatial reordering of manufacture. Accounting, Organizations and Society, 19(1), 15-43.

Miller, P., \& O'Leary, T. (2007). Mediating instruments and making markets: Capital budgeting, science and the economy. Accounting, Organizations and Society 32 (7-8), 701-734.

Miller, P., \& Rose, N. (1990). Governing economic life. Economy and Society, 19, 1-31.

Miller, P., \& Rose, N. (2008). Governing the present: Administering economic, social and personal life. Cambridge: Polity.

Miller, P., Kurunmäki, L., \& O’Leary, T. (2008). Accounting, hybrids and the management of risk. Accounting, Organizations and Society, 33(7/8): 942-967.

NWRA (2003). Implementing Action for Sustainability: An Integrated Appraisal Toolkit for the North West 2003. North West Regional Assembly.

Neu, D. (2000). Accounting and accountability relations: Colonization, genocide and Canada's first nations. Accounting Auditing \& Accountability Journal, 13, 268-288.

Neu, D. (2006). Accounting for public space. Accounting, Organizations and Society, 31, 391-414.

Neu, D., \& Heincke, M. (2004). The subaltern speaks: Financial relations and the limits of governmentality. Critical Perspectives on Accounting, 15, 179-206.

Nyamori, R. O. (2009). Construction and effects of markets in a local authority in New Zealand. Accounting, Auditing \& Accountability Journal, 22, 1055-1086.

O' Dwyer, B. (2003a). Qualitative data analysis: illuminating a process for transforming a 'messy' but 'attractive' 'nuisance'. In C. Humphrey, \& B. Lee (Eds.), The real life guide to accounting research. London: Elsevier.

O'Dwyer, B. (2003b). Conceptions of corporate social responsibility: the nature of managerial capture. Accounting, Auditing and Accountability Journal, 16(4), 523-57.

O'Dwyer, B. (2005). The construction of a social account: A case study in an overseas aid agency. Accounting, Organizations and Society, 30, 279-296. 
Obama, B. (2013). Remarks by the President on Climate Change. Washington: The White House.http://www.whitehouse.gov/the-press-office/2013/06/25/remarks-president-climate-change. Accessed 13.09.13.

Oels, A. (2005). Rendering climate change governable: from biopower to advance liberal government? Journal of Environmental Policy and Planning, 7(3), 185-207.

Power, M. (2004). The risk management of everything: Rethinking the politics of uncertainty. London: Demos.

Power, M. (2007). Organised uncertainty: Designing a world of risk management. Oxford: Oxford University Press.

Pretty, J. (2011). Interdisciplinary progress in approaches to address social-ecological and ecocultural Systems. Environmental Conservation 38, 127-139.

Puxty, A. G. (1991). Social accountability and universal pragmatics. Advances in Public Interest Accounting, 4, 35-45.

Radcliffe, V. S. (1998). Efficiency audit: An assembly of rationalities and programmes. Accounting, Organizations and Society, 23, 377-410.

Rahaman, A. S., Everett, J., \& Neu, D. (2007). Accounting and the move to privatize water services in Africa. Accounting, Auditing \& Accountability Journal, 20, 637-670.

Rose, N. (1991). Governing by numbers: figuring out democracy. Accounting, Organizations and Society, 16(7), 673-693.

Russell, S. L., \& Thomson, I. (2009). Analysing the role of sustainable development indicators in accounting for and constructing a Sustainable Scotland. Accounting Forum, 33, 225-244.

Schaltegger, S. and Wagner, M. (2006). Integrative management of sustainability performance, measurement and reporting. International Journal of Accounting, Auditing and Performance Evaluation, 3, 1-19.

Spence, L., \& Rinaldi, L (in press) Governmentality in accounting and accountability: A case study of embedding sustainability in a supply chain, Accounting, Organizations and Society, In Press, Corrected Proof.

The Prince's Charities (Eds.) (2009). Accounting for Sustainability, Practical Insights: A summary of Case Studies in Embedding and Reporting Sustainability. London: Clarence House.

Thomson, I. (2007). Accounting and Sustainability: Mapping the Terrain. In Bebbington, O’Dwyer and Unerman, Sustainable Accounting and Accountability, Routledge, UK.

Thomson, I., \& Georgakopoulos, G. (2010). Building from the bottom, inspired from the top: Accounting for Sustainability in the Environment Agency. In A. Hopwood, J. Unerman, \& J.Fries (Eds.), Accounting for sustainability: Practical insights (pp.129-148). London: Earthscan.

UK Treasury (2012). Public Sector Annual Reports: Sustainability Reporting, www.hmtreasury.gov.uk/frem sustainability.htm

Unerman, J. \& O’Dwyer, B. (2010). Evolution of Risk, Opportunity and the Business Case in Embedding Connected Reporting in BT. In A. Hopwood, J. Unerman, \& J. Fries (Eds.), Accounting for sustainability: 
practical insights (pp.149 - 170). UK: Earthscan.

Vaivio, J. (2006). The accounting of "The Meeting": Examining calculability within a "Fluid" local space. Accounting, Organizations and Society, 31, 735-762.

Van Helden, G, Aardema, H. Ter Bogt, H., \& Groot, T. (2010). Knowledge creation for practice in public sector management accounting by consultants and academics: Preliminary findings and directions for future research. Management Accounting Research (21) 2 85-94.

Walker, S. P. (2010). Child accounting and "the handling of human souls". Accounting, Organizations and Society, 35, 628-657.

West Sussex Sustainability Forum (2005). A Time for Action: A strategy for a sustainable West Sussex. West Sussex County Council.

Wise, M. (1988). Mediating Machines, Science in Context, 2(1) 77-113.

Wise, N. Ed. (1995). The Values of Precision, Princeton University Press, UK.

Wise, N., \& Smith, C. (1989a). Work and waste: Political Economy and natural philosophy in nineteenth century Britain (1). History of Science xxvii, 263-301.

Wise, N., \& Smith, C. (1989b). Work and waste: Political Economy and natural philosophy in nineteenth century Britain (2). History of Science xxvii, 391-449.

Wise, N., \& Smith, C. (1990). Work and waste: Political Economy and natural philosophy in nineteenth century Britain (3). History of Science xxviii, 221-256.

WSCC (2009a). With You, For You - A strategy for West Sussex 2009-2013. West Sussex County Council.

WSCC (2009b). Corporate Sustainability Programme 2009-13. West Sussex County Council. Yin, R.K. (2003). Case Study Research: Design and Methods ( $3^{\text {rd }}$ ed., Vol. 5). Sage, Beverly Hills. Young, J. J. (1995). Getting the accounting "right": Accounting and the savings and loan crisis. Accounting, Organizations and Society, 20, 55-80. 